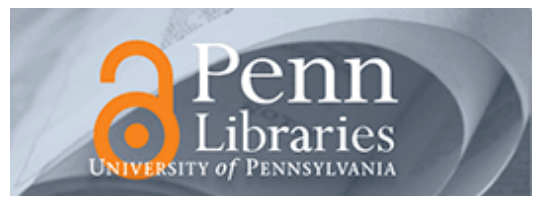

University of Pennsylvania

ScholarlyCommons

Marketing Papers

Wharton Faculty Research

\title{
$5-2011$
}

\section{The Effect of Market Structure on Cellular Technology Adoption and Pricing}

Katja Seim

University of Pennsylvania

Brian Viard

Follow this and additional works at: https://repository.upenn.edu/marketing_papers

Part of the Economic Policy Commons, Law and Economics Commons, Marketing Commons, Marketing Law Commons, and the Technology and Innovation Commons

Recommended Citation

Seim, K., \& Viard, B. (2011). The Effect of Market Structure on Cellular Technology Adoption and Pricing. American Economic Journal: Microeconomics, 3 (2), 221-251. http://dx.doi.org/10.1257/mic.3.2.221

This paper is posted at ScholarlyCommons. https://repository.upenn.edu/marketing_papers/416

For more information, please contact repository@pobox.upenn.edu. 


\title{
The Effect of Market Structure on Cellular Technology Adoption and Pricing
}

\begin{abstract}
We examine how structural changes in the mobile telecommunications industry between 1996, when local markets were duopolies, and 1998, when varing degrees of regulated entry had occurred, affected firms' product offerings and nonlinear pricing strategies. We relate firms' digital technology adoption and the characteristics of their calling plan menus to the amount of entry in local markets. We find that entry induces firms to offer larger menus with more evenly spread plans, both directly and by accelerating the introduction of digital menus with such features. Prices decline with entry, in particular for high-valuation consumers who benefit from steeper quantity discounts.
\end{abstract}

\section{Disciplines}

Business | Economic Policy | Law and Economics | Marketing | Marketing Law | Technology and Innovation 


\title{
The Effect of Market Structure on Cellular Technology Adoption and Pricing ${ }^{\dagger}$
}

\author{
By Katua Seim and V. Brian Viard*
}

\begin{abstract}
We examine how structural changes in the mobile telecommunications industry between 1996, when local markets were duopolies, and 1998, when varying degrees of regulated entry had occurred, affected firms' product offerings and nonlinear pricing strategies. We relate firms' digital technology adoption and the characteristics of their calling plan menus to the amount of entry in local markets. We find that entry induces firms to offer larger menus with more evenly spread plans, both directly and by accelerating the introduction of digital menus with such features. Prices decline with entry, in particular for high-valuation consumers who benefit from steeper quantity discounts. (JEL L11, L13, L96, L98, O33)
\end{abstract}

$\mathbf{W}$ ireless carriers offered on average 5.9 different calling plans in a market in 1996. By 2002, that number had increased to 17.5 before falling to 3.7 by 2007. ${ }^{1}$ In part, these changes reflect the introduction, and later elimination, of vertically differentiated services, such as different transmission technologies and sizes of calling areas. They also reflect adjustments in the carriers' use of second-degree price discrimination in response to factors such as increasing demand heterogeneity, increased availability of wireless spectrum, and changes in market structure.

Only a few theoretical results and limited empirical research are available to inform how market structure affects firms' second-degree price discrimination strategies and consequent welfare effects. Even less is known about its simultaneous impact on firms' product offerings and use of price discrimination. This interaction has important welfare consequences in many empirical settings, particularly communications and information industries, such as wireless communications, Internet access, and content distribution. These industries experience frequent market structure changes through reorganizations or new entry, frequent product innovations due to technological change, and price discrimination based on menus of nonlinear price schedules.

\footnotetext{
* Seim: The Wharton School, University of Pennsylvania, 3620 Locust Walk, Philadelphia, PA 19104 (e-mail kseim@wharton.upenn.edu); Viard: Cheung Kong Graduate School of Business, 20/F, Tower E2, Oriental Plaza, 1 East Chang An Avenue, Beijing, China 100738 (e-mail: brianviard@ckgsb.edu.cn).We would like to thank Michael Grubb, John Johnson, and Li Xing for excellent research assistance, Anja Lambrecht, Philip Leslie, John Parapatt, and Catherine Tucker for helpful comments, and Dan Ackerberg for providing us with computer code for a related problem. This research was supported by the NET Institute and the Stanford Center for Electronic Business and Commerce.

$\dagger$ To comment on this article in the online discussion forum, or to view additional materials, visit the article page at http://www.aeaweb.org/articles.php?doi=10.1257/mic.3.2.221.

'Authors' calculations based on data from Kagan World Media and MyRatePlan.com, LLC.
} 
In this paper, we assess the impact of market structure on firms' price discrimination strategies, both directly, through competitive interaction, and indirectly, through its influence on how quickly firms market new services and discontinue old ones. We employ comprehensive, geographically detailed data on nonlinear pricing plans offered by wireless carriers in 1996 and in 1998. Between the two years, personal communication services (PCS) providers entered wireless duopoly markets and incumbents began introducing digital service that improved on the existing analog service in call features and spectrum management. In our setting we can assess the relative importance of the direct and the indirect effect, via technology adoption, of market structure on pricing. We find that the median indirect effect amounts to 33.45 percent of the overall effects of market structure, reflecting that carriers provide both more plan variety and greater price decreases for the new than for the old technology. We find that indirect effects are less significant in affecting the spacing of plans along the usage spectrum.

Theoretical work on the direct effect of competition (including Shmuel S. Oren, Stephen A. Smith, and Robert B. Wilson 1983; Esther Gal-Or 1988; Daniel F. Spulber 1989; and Lars A. Stole 1995) focuses on the relationship between the number of firms and the breadth and curvature of nonlinear price schedules. A common finding is that greater competition leads firms to lower their price schedules toward marginal cost, increases consumer participation in the market, and reduces welfare distortions between high- and low-valuation consumers. Justin P. Johnson and David P. Myatt (2003, 2006) and Huanxing Yang and Lixin Ye (2008) consider the effect of changes in market structure when firms are horizontally differentiated. The implications of these papers depend on the initial level of competition (i.e., do firms directly compete or have local monopolies), making them difficult to relate to an empirical setting.

Theoretical work relevant to the indirect effect of market structure via new product pricing focuses on the strategic determinants of product diffusion speed, specifically the possibility that a firm would adopt a product preemptively to deter or delay adoption by other firms. Jennifer F. Reinganum (1981a, 1981b) points to two offsetting effects: lower firm concentration increases the competitive pressure on an individual firm to gain a relative advantage early, but it also drives down post-adoption profits, inducing firms to wait for adoption costs to decline. Drew Fudenberg and Jean Tirole (1985) imply that, when competition increases so too does technology adoption because there are more opportunities for firms to steal business. In aggregate, this literature yields inconclusive predictions for the effect of market structure on the speed of diffusion (see Heidrun C. Hoppe 2002 for a more extensive review). However, we show in the Appendix that by tailoring a model to the regulated entry observed in our setting, theoretical predictions are consistent with our empirical finding that entry accelerates adoption when incumbents' profits fall more when they remain with an old technology than when they upgrade to a new, substitute technology. We argue that the latter condition is likely to hold in our setting as well as in communications and information industries more broadly.

Previous empirical results on the effect of market structure on adoption speed vary: Sharon G. Levin, Stanford L. Levin, and John B. Meisel (1987), Timothy H. Hannan and John M. McDowell (1984), and Massoud Karshenas and Paul L. Stoneman (1993), 
respectively, find a negative, positive, and no significant relationship between market concentration and adoption speed. A difficulty in this previous work is accounting for unobserved drivers of both entry and product introduction strategies. The entry that occurred in wireless markets after 1996 resulted from regulatory intervention, which limits the role of unobserved profit shifters in determining market structure. In addition, the levels of entry experienced by 1998 varied across local markets because of exogenous differences in geographic and regulatory features that affect the time required to build a sufficiently dense transmission network. Our empirical finding of a positive relationship between market concentration and adoption speed thus benefits from a more controlled setting than was possible in previous work.

We find that additional competition leads to increased price discrimination both directly, through increased plan variety, and indirectly, through quicker adoption and marketing of the new service, and that both effects are important. In markets with more competition, firms are more likely to upgrade and, if they do, phase out more analog calling plans and introduce more digital calling plans than their counterparts in less competitive markets. We show further that firms generally decrease the clustering of contracts more in markets with more entry, suggesting that they respond to intensified competition by attempting to steal business rather than by increasing customer segmentation.

We also find that competition induces firms to tailor their offerings to the customer group whose demand is best served by their chosen technology. Incumbents who continue to offer capacity-constrained analog service expand their share of low-usage plans more when facing more competitors. Digital entrants and incumbents who fully replaced analog with capacity-unconstrained digital service increase the share of highusage plans more when facing more entry. High-usage customers also gain more from price decreases due to entry. Consistent with evidence provided by Meghan Busse and Marc Rysman (2005), we find that while firms reduce prices in general, quantity discounts are larger in markets with more entry. Competition again plays a direct role, with entry decreasing price, and an indirect role, with firms that offer digital plans also offering steeper discounts than their non-digital competitors.

These results have important consequences for telecommunications regulation. In most countries regulators have a direct impact on market structure through licensing practices, spectrum allocation or auctions, and merger reviews. In doing so, it is important for regulators to consider the impact of alternative market structures on the improvement of existing technological standards and subsequent pricing. For example, in deciding how much spectrum to make available for wireless broadband services, regulators should consider the incentives that ensuing competition will create for incumbents to phase out narrowband or upgrade existing broadband technologies and the menu of prices they offer. Similarly, the ongoing consolidation in the wireless industry may benefit consumers through improved call quality and coverage and cost savings generated by scale economies. However, our results suggest that increased concentration may also slow efforts to introduce next-generation services and alter providers' pricing, with high-valuation customers being the most severely affected. Our results complement theoretical work emphasizing that regulators consider the role of substitutes in pressuring incumbents to upgrade their offerings (see Michael H. Riordan 1992). 


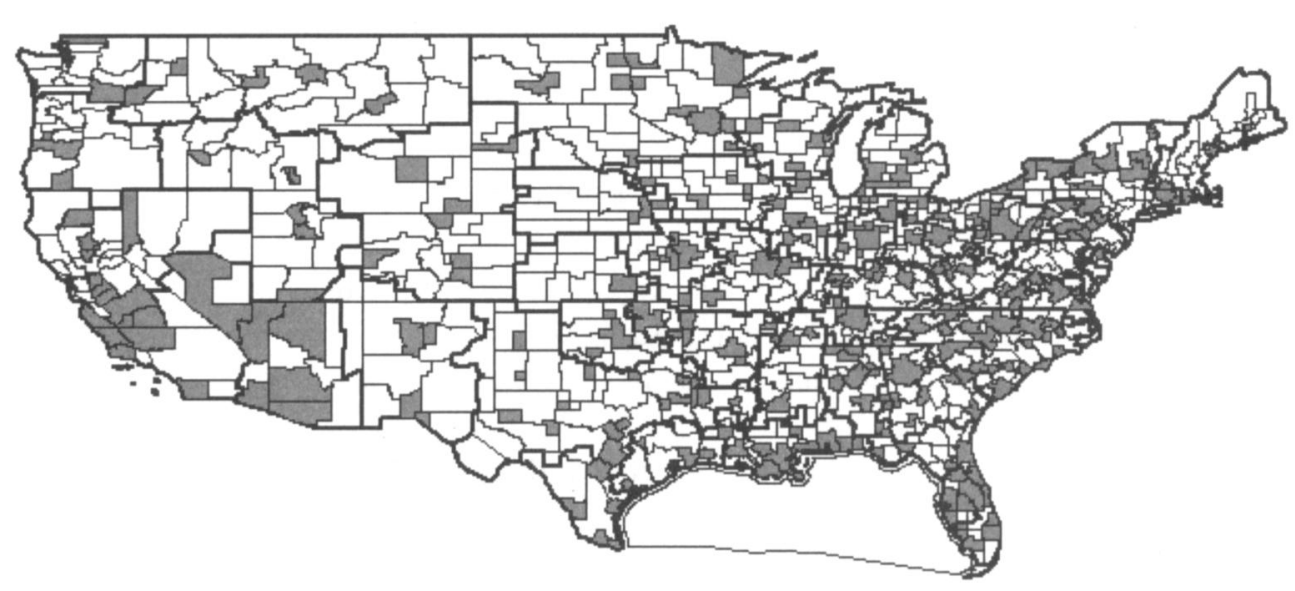

Figure 1. Major Trading Areas and Cellular Market Areas

Notes: This map shows the geographic market areas for cellular service. The dark-bordered regions are the 51 MTAs and the light-bordered areas are the CMAs. Shaded CMAs denote the set of 100 largest cellular markets in 1996.

\section{Mobile Telecommunications Markets in the Late 1990s}

The US cellular phone industry originated in 1981, when the Federal Communications Commission (FCC) awarded two licenses per cellular market area (CMA) to provide cellular telephone services in 306 metropolitan markets and 428 FCC-designated rural markets covering the entire country (see Figure 1). The duopoly structure existed until the introduction of PCS. ${ }^{2}$ Between December 1994 and January 1997, the FCC awarded 2,074 PCS spectrum licenses, six in each market. The geographic market definition used for PCS spectrum differed from that for cellular markets. Fifty-one major trading areas (MTAs), shown inside bold-faced boundaries in Figure 1, divided the country into regions the size of multiple cities or states, which were subdivided into basic trading areas (BTAs) the same size as or slightly larger than the corresponding CMA. We utilize two snapshots of the universe of residential wireless contracts from the 100 largest CMAs (shown as shaded areas in Figure 1) provided by Kagan World Media to investigate how market conduct changed with entry. The first snapshot was taken in February 1996, when all but two markets operated as duopolies, ${ }^{3}$ and the second in March 1998.

Concurrent with the allocation of PCS licenses, Nextel Communications entered by transitioning from providing mobile radio services to offering wireless services. Nextel began a national rollout of its service in September 1996. By 1998, Nextel had entered 71 of the 100 largest cellular markets. Despite Nextel's initial focus on

\footnotetext{
${ }^{2}$ Cellular pricing under this duopoly structure is the topic of Philip M. Parker and Lars-Hendrik Röller (1997) and Busse (2000).

${ }^{3}$ The two exceptions are the Baltimore and Washington CMAs, which we dropped from the estimation sample. Both markets experienced entry by three firms by 1998.
} 
business customers, we treat it as a viable competitor to the cellular incumbents, similar to the PCS entrants.

With the conclusion of the PCS auctions, cellular incumbents faced potential entry of one specialized mobile operator and six PCS providers. Two main factors drive the number of competitors actually operating in a market by 1998 . First, due to the bankruptcy of several winning bidders in small business auctions, 347 licenses remained initially inactive and were re-auctioned only in April 1999. Second, there is a significant lag between license award and service initiation while the carrier builds a network of towers to broadcast signals of sufficient quality to its users' phones. ${ }^{4}$ This time lag is commonly referred to as the "build-out" delay. Since Nextel's network is cellular-like, similar build-out requirements constrained its rollout of service. The time it takes to deploy service depends on endogenous market characteristics such as the potential subscriber base. Other characteristics, such as the market's geographic area and local land-use regulations that affect the difficulty and cost of constructing the required tower network, provide exogenous variation in the number of competitors across markets at a given time.

Table 1 shows the entrants' launch dates by quarter for the largest 100 markets from 1995 to 1998. By March 1998, on average 4.31 providers offer wireless service in a CMA. Across markets, five cities had no entry, 25 cities entry by one firm, 27 cities entry by two firms, 33 cities entry by three firms, and ten cities entry by four firms by 1998 .

The networks that the entrants built used digital technologies. Digital technologies improved the efficiency of spectrum use and the quality and reliability of service. By allowing for new features such as call waiting and caller ID, they increased vertical differentiation in service provision. Prior to the introduction of digital technology, vertical differentiation was primarily due to differences in call quality in the local calling area. The only significant horizontal differentiation was brand reputation unrelated to vertical quality.

As of 1998, digital service had a limited coverage area, which was frequently restricted to the user's local calling area since the providers' use of four incompatible technology standards increased the chance of inoperability when traveling. ${ }^{5}$ Initially, therefore, analog service continued to be attractive to low-usage customers or customers who traveled frequently outside their local region. With the increased diffusion of digital technologies, however, demand for digital service quickly exceeded that for analog, with approximately 50 percent of subscribers using digital technologies by late 1999 (Cellular Telecommunications and Internet Association 2000).

In 1996 the incumbents employed analog technology almost exclusively, and in rare cases immature digital technologies, and could choose to upgrade their existing analog networks to digital. Adding digital capabilities to an existing network usually involved minimal hardware additions at the towers along with software upgrades and a significant amount of system optimization. Frequently, incumbents did not require

\footnotetext{
${ }^{4}$ The FCC required PCS licensees to meet specific coverage requirements, amounting to providing adequate service to between 25 and 33 percent of the market's population within five years.

${ }^{5}$ The cellular and PCS providers used one of three digital technology standards, CDMA, TDMA, or GSM. Nextel used Motorola's digital iDEN technology.
} 
Table 1-Entrants' Activation of Systems by Launch Quarter in ToP 100 Cellular MARKETS, Q4 1995-Q2 1998

\begin{tabular}{lccc}
\hline $\begin{array}{l}\text { Quarter of } \\
\text { launch }\end{array}$ & $\begin{array}{c}\text { Number of } \\
\text { launches }\end{array}$ & $\begin{array}{c}\text { Average build-out time } \\
\text { (months) }\end{array}$ & $\begin{array}{c}\text { Average } \\
\text { market size }\end{array}$ \\
\hline Q4-1995 & 2 & 11.0 & $3,538,229$ \\
Q1-1996 & - & - & - \\
Q2-1996 & 2 & 13.0 & $1,062,081$ \\
Q3-1996 & 13 & 16.6 & $1,553,067$ \\
Q4-1996 & 39 & 20.2 & $2,031,327$ \\
Q1-1997 & 35 & 23.4 & $1,884,427$ \\
Q2-1997 & 28 & 26.0 & $2,205,694$ \\
Q3-1997 & 31 & 28.2 & $2,269,856$ \\
Q4-1997 & 34 & 30.0 & $1,746,194$ \\
Q1-1998 & 12 & 33.1 & $2,062,024$ \\
Q2-1998 & 22 & 26.8 & $1,900,680$ \\
Total & 218 & 25.3 & $1,951,804$ \\
\hline
\end{tabular}

Note: Average build-out times are computed for PCS entrants only as the delay between license award and system activation.

Source: PCS Week, various issues, companies' public filings.

any additional towers to provide digital service, which allowed them to avoid the zoning and other difficulties associated with identifying new tower locations that the PCS entrants faced. Cellular incumbents were thus able to roll out digital service quickly in response to changes in demand or supply. ${ }^{6}$ We characterize the upgrade made by such firms as an adoption decision followed by a fixed, brief implementation time.

Incumbents' timing of and approach to digital deployment varied significantly. By 1998, 66.32 percent of all incumbents were offering digital calling plans; 7.77 percent offered only digital plans within a market; ${ }^{7}$ and 58.50 percent gave customers a choice between analog and digital technology by offering calling plans for both; 33.68 percent of providers had not yet begun digital deployment by 1998 .

During the sample period most providers held licenses to operate in only a small number of markets. Of the 24 cellular providers in the top 100 markets in 1996, fifteen firms operated in at most five of the top 100 cellular markets, and only five carriers offered service in more than fifteen markets. Because providers had to pay other providers to terminate or originate calls outside these limited networks, they offered only local calling plans during the sample period. ${ }^{8}$

The calling plans consist of three-part tariffs. To evaluate carriers' nonlinear pricing we define a "plan family" as the set of plans offered by one carrier that differ in their fixed fees and numbers of included peak minutes ("allowances") but have a common service technology and share other features, such as calling area and contract duration. Since regional and national plans were not available, a PCS

\footnotetext{
${ }^{6}$ See Jason Meyers (1997) for a more detailed description of the digital upgrade process.

${ }^{7}$ The FCC's rules require that all incumbent cellular carriers continued to provide analog service through 2008. However, the carriers are not required to offer or market new analog service plans. In contrast, other mobile telephony carriers such as the PCS providers are not required to provide analog service.

${ }^{8}$ With the gradual build-out of larger networks, carriers introduced calling plans with larger regional or national calling areas subsequent to our sample period.
} 
provider in our data offers one digital "plan family" in a local market, while a cellular provider that has introduced digital service but continues to market analog service offers a choice of two "plan families."

Table 2 shows that a plan family offered by the incumbents in 1996 consisted of, on average, 5.89 individual analog plans; the number of plans offered by a provider ranged from three to eight. By 1998, incumbents had introduced 128 digital plan families across the 98 markets, while continuing to offer 178 analog plan families. Relative to 1996, the number of plans in an analog plan family decreased by 0.07 on average; however, the standard deviation of 1.92 plans reflects an uneven adjustment. A large fraction of providers offered both analog and digital plans simultaneously, with their digital calling plan families consisting of 5.06 plans on average. Table 2 also shows the variation in fixed fees and allowances across plans in 1998. ${ }^{9}$

This variation, together with the variation in entry and the clear definition of markets in this industry, yields an attractive setting in which to test the effect of market structure on technology adoption timing and price discrimination strategies.

\section{Entry, Technology Adoption, and Nonlinear Pricing: Results}

Greater competition in cellular markets has the potential to change firms' nonlinear pricing practices through two channels. With more competition, firms may adjust both the number of options offered to customers in their menu of plans and the placement of their plans. These are the direct effects of entry. At the same time, additional competition may change incumbents' incentives to adopt the digital technology, leading them to make changes to the offered pricing menus if digital plan families differ from analog. These are the indirect effects of entry.

We begin with a discussion of the effects of entry on plan introductions, before turning to an analysis of plan placement, investigating changes in placement overall and for customers of different usage types. We then quantify the overall effect on price levels. As we discuss our results, we relate them to the available theoretical predictions.

\section{A. Effect on Plan Introductions}

We first consider incumbents' incentives to introduce additional plans in response to entry. We use the change between 1996 and 1998 in the number of calling plans incumbents offer to test whether they respond to changes in competition, either directly, by changing the size of plan families, or indirectly, by complementing or replacing existing analog with digital offerings. We find that incumbents were more likely to increase calling plan variety for new or continuing technologies and to phase out additional calling plans for obsolete technologies in markets with more competitors.

\footnotetext{
${ }^{9}$ The data include detailed calling plan descriptors, which confirm that changes in the menu of plans reflect the introduction or elimination of distinct calling plans. We focus on two key features of cellular contracts, the plan's monthly fixed fee and allowance. Along these two dimensions, the plan offerings differ significantly within each plan family.
} 
Table 2-Descriptive Statistics, 98 Largest Cellular Markets

\begin{tabular}{|c|c|c|c|c|c|}
\hline Variable & $\begin{array}{l}\text { Obser- } \\
\text { vations }\end{array}$ & Mean & SD & Minimum & Maximum \\
\hline \multicolumn{6}{|l|}{ Incumbents' plan family characteristics } \\
\hline Number of plans in analog family, 1996 & 193 & 5.89 & 1.30 & 3.00 & 8.00 \\
\hline Change in the number of plans offered, 1996-1998 & 193 & 2.80 & 3.47 & -5.00 & 12.00 \\
\hline Analog plan families, if offered & 178 & -0.07 & 1.92 & -6.00 & 5.00 \\
\hline Digital plan families, if offered & 128 & 5.06 & 1.58 & 2.00 & 9.00 \\
\hline Share, analog plan families, 1998 & 306 & 0.58 & 0.49 & 0.00 & 1.00 \\
\hline \multicolumn{6}{|l|}{ Incumbents' plan characteristics, 1998} \\
\hline Fixed fee, analog plans & 1,017 & 72.06 & 64.87 & 9.95 & 592.99 \\
\hline Allowance, analog plans & 1,017 & 301.05 & 470.98 & 0.00 & $3,560.00$ \\
\hline Fixed fee, digital plans & 713 & 73.24 & 47.96 & 14.95 & 279.99 \\
\hline Allowance, digital plans & 713 & 555.74 & 558.04 & 0.00 & $3,000.00$ \\
\hline \multicolumn{6}{|l|}{ Incumbents' technology choice by market, 1998} \\
\hline Analog only (provider share) ${ }^{1}$ & 193 & 0.34 & 0.47 & 0.00 & 1.00 \\
\hline Digital only (provider share) ${ }^{1}$ & 193 & 0.08 & 0.27 & 0.00 & 1.00 \\
\hline Mixed technology (provider share) ${ }^{1}$ & 193 & 0.59 & 0.49 & 0.00 & 1.00 \\
\hline \multicolumn{6}{|l|}{ Incumbent characteristics } \\
\hline Number of markets present & 24 & 12.75 & 15.59 & 1.00 & 48.00 \\
\hline Small network (provider share) & 24 & 0.63 & 0.49 & 0.00 & 1.00 \\
\hline Large network (provider share) & 24 & 0.21 & 0.41 & 0.00 & 1.00 \\
\hline \multicolumn{6}{|l|}{ Market characteristics } \\
\hline Population (000) & 98 & $1,524.66$ & $1,662.93$ & 175.20 & $9,519.34$ \\
\hline Average commuting time (mins) & 98 & 24.58 & 3.25 & 19.00 & 38.90 \\
\hline Household income $(000)$ & 98 & 44.03 & 7.18 & 31.05 & 74.34 \\
\hline Percent with BA or more & 98 & 24.41 & 5.43 & 13.09 & 41.66 \\
\hline Heterogeneity in commuting time & 98 & 87.57 & 1.06 & 84.58 & 89.98 \\
\hline Heterogeneity in income & 98 & 92.46 & 0.23 & 91.68 & 93.09 \\
\hline Heterogeneity in educational attainment & 98 & 83.97 & 1.82 & 77.14 & 86.80 \\
\hline Wharton Residential Urban Land Regulation Index & 98 & 0.05 & 0.74 & -1.28 & 1.89 \\
\hline Percentage of MSA area classified commercial & 98 & 2.95 & 3.23 & 0.31 & 22.97 \\
\hline
\end{tabular}

${ }^{1}$ The unit of observation is the market and provider, measuring the percent of firms that offer a given technology in the market.

Econometric Model.-We estimate a system of three nonlinear equations using full information maximum likelihood (FIML), which predicts the chosen adjustment in the size of the plan family and technology adoption while controlling for correlations in unobserved market attributes that render entry endogenous. Our estimation accounts for the discreteness of our data. We specify the change in number of plans between 1996 and 1998, which ranges from -6 to 9 in the data, for incumbent $i$ in market $m$ offering technology $t \in\{$ analog, digital $\}$ as an ordered probit model:

(1) $\Delta$ Plans $_{\text {imt }}=\left\{\begin{array}{l}-6 \quad \text { if } f^{P}\left[\alpha^{P}, \beta^{P}, \mathbf{Z}_{i m t}^{P}\right]+\xi_{i m t}^{P} \leq C_{-5}^{P} \\ l \quad \text { if } C_{l}^{P}<f^{P}\left[\alpha^{P}, \beta^{P}, \mathbf{Z}_{\text {imt }}^{P}\right]+\xi_{\text {imt }}^{P} \leq C_{l+1}^{P}, \quad l=-5, \ldots, 8, \\ 9 \quad \text { if } C_{9}^{P}<f^{P}\left[\alpha^{P}, \beta^{P}, \mathbf{Z}_{\text {imt }}^{P}\right]+\xi_{i m t}^{P},\end{array}\right.$ 
where the parameter $C_{l}^{P}$ implies a cutoff for the unobservable $\xi_{\text {imt }}^{P}$ that entails moving from a change in plans of $l-1$ to $l{ }^{10}$ We allow the number of entrants to flexibly affect the change in the number of plans by estimating an effect that differs by technology and plan type, controlling for market characteristics:

$$
\begin{aligned}
f^{P}\left[\alpha^{P}, \beta^{P}, \mathbf{Z}_{\text {imt }}^{P}\right] \equiv & \alpha^{P}+\beta_{1}^{P} \text { Prov_Tech }_{i m}+\beta_{2}^{P} \text { Plan_Type }_{i m} \\
& +\beta_{3}^{P}\left(\text { Prov_Tech }_{i m}\right)\left(\text { Plan_Type }_{i m}\right)\left(\text { Entrants }_{m}\right)+\beta_{\geq 4}^{P} \mathbf{X}_{\text {im }}^{P} .
\end{aligned}
$$

Prov_Tech $_{i m}=\left[\right.$ Prov_Analog $_{i m}$ Prov_Mixed $_{i m}$ Prov_Digital $\left._{i m}\right]$ are dummy variables indicating whether firm $i$ offers analog-only, mixed, or digital-only technologies in 1998, Plan_Type $_{i m}=\left[\right.$ Plans_Analog $_{i m}$ Plans_Digital $\left._{i m}\right]$ are dummy variables indicating whether firm $i$ 's plan family is analog or digital, and Entrants $s_{m}$ is the number of PCS entrants by 1998 .

We follow earlier studies of the cellular industry, such as Busse (2000) and Eugenio J. Miravete and Röller (2004), to control for market demographics that affect firms' choices of plan variety and include these in $\mathbf{X}_{i m}^{P}$. These include the CMA population $\left(\mathrm{Pop}_{m}\right)$ as a measure of market size, mean commuting time in minutes $\left(\right.$ Commute $\left._{m}\right)$ as a proxy for the additional value of a cellular phone to frequent drivers, average household income $\left(\right.$ Income $\left._{m}\right)$, and the educational attainment of the head of houseold $(B A+m)$. Since plan variety reflects primarily demand heterogeneity, rather than size, we compute Herfindahl-type indices for the demographic variables in each market, representing the probability of two randomly selected CMA residents falling into the same demographic category. ${ }^{11}$ Table 2 provides descriptive statistics for the variables and Table 3 summarizes the variables and their sources. We also include firm fixed-effects in $\mathbf{X}_{i m}^{P}$ to control for firm-specific differences in the response to entry.

We specify firm $i$ 's decision to adopt digital technology as a probit model:

$$
\text { Digital }_{i m}= \begin{cases}1 & \text { if } f^{D}\left[\alpha^{D}, \beta^{D}, \mathbf{Z}_{i m}^{D}\right]+\xi_{i m}^{D}>0 \\ 0 & \text { otherwise }\end{cases}
$$

controlling for firm and market factors that might affect adoption:

$$
\begin{aligned}
f^{D}\left[\alpha^{D}, \beta^{D}, \mathbf{Z}_{i m}^{D}\right] \equiv & \alpha^{D}+\beta_{1}^{D} \text { Entrants }_{m}+\beta_{2}^{D} B A+m+\beta_{3}^{D} \text { Commute }_{m} \\
& +\beta_{4}^{D} \text { Pop }_{m}+\beta_{5}^{D} \text { Income }_{m}+\beta_{6}^{D} \text { Large }_{S c i}+\beta_{7}^{D} \text { Small }_{S c i} .
\end{aligned}
$$

\footnotetext{
${ }^{10}$ An alternative specification would be a count-data model. In our setting, the ordered response model has the benefit that it naturally allows for negative values of the outcome variable. See Colin A. Cameron and Pravin $\mathrm{K}$. Trivedi (2005) for a discussion of the advantages of discrete choice models when modeling changes in counts, and Cameron and Trivedi (1986) for a comparison of the performance of ordered and count-data estimators. A downside to the ordered probit model is that extrapolation beyond the observed maximum change in plans offered is difficult. We focus on interpreting the effects of changes in the estimated parameters within the observed sample range of the plan change variable only.

${ }^{11}$ The incumbents' choices to introduce calling plans may reflect growth or increasing heterogeneity in market demand. Unfortunately, market-specific changes in the cellular subscriber base are not available.
} 
TABle 3-Variable Description and Data Sources

\begin{tabular}{|c|c|c|}
\hline Variable & Description & Data source \\
\hline$\Delta$ Plans & $\begin{array}{l}\text { Change in the number of plans of a given technology offered } \\
\text { by incumbents in each market. }\end{array}$ & Kagan World Media \\
\hline Plan-Family Herfindahl ${ }^{1}$ & $\begin{array}{l}\text { Herfindahl index based on share of minutes allocated to each } \\
\text { calling plan. }\end{array}$ & \\
\hline Share of high-usage plans & $\begin{array}{l}\text { Number of calling plans with an allowance above } 180 \text { minutes } \\
\text { as a share of family's total number of plans. }\end{array}$ & \\
\hline Prov_Analog & Indicator: Provider offers only analog service in 1998. & \\
\hline Prov_Mixed & $\begin{array}{l}\text { Indicator: Provider offers separate analog and digital plan } \\
\text { choices in } 1998 .\end{array}$ & \\
\hline Prov_Digital & Indicator: Provider offers only digital service in 1998. & \\
\hline Plans_Analog & Indicator: Plan family's technology is analog. & \\
\hline Plans_Digital & Indicator: Plan family's technology is digital. & \\
\hline Entrants & Number of entrants into the market by 1998 . & \\
\hline Large $_{S c}$ & $\begin{array}{l}\text { Indicator: Provider offers cellular service in more than } 15 \text { of } \\
\text { the top } 100 \text { cellular markets. }\end{array}$ & \\
\hline Small $_{s c}$ & $\begin{array}{l}\text { Indicator: Provider offers cellular service in at most } 5 \text { of the } \\
\text { top } 100 \text { cellular markets. }\end{array}$ & \\
\hline Pop & CMA population in thousands. & Census 2000 \\
\hline Area & CMA land area in square miles. & \\
\hline Commute & Average commuting time in minutes. & \\
\hline Income & Household income in thousands of dollars. & \\
\hline $\mathbf{B A}+$ & Percent of MSA population with at least a BA degree. & \\
\hline Heterogeneity, time ${ }^{2}$ & $\begin{array}{l}\text { Heterogeneity index. Groups classify shares of workers by } \\
\text { commuting time. Categories begin at } 5,10,15,20,25,30,35 \text {, } \\
40,45,60 \text {, and } 90 \text { minutes. }\end{array}$ & \\
\hline Heterogeneity, income ${ }^{2}$ & $\begin{array}{l}\text { Heterogeneity index. Groups classify household shares by in- } \\
\text { come in thousands, beginning at } \$ 10 \text { to } \$ 50 \text { in } \$ 5 \text { increments, } \\
\$ 60, \$ 75, \$ 100, \$ 125, \$ 150 \text {, and } \$ 200 \text {. }\end{array}$ & \\
\hline $\begin{array}{l}\text { Heterogeneity, educational } \\
\text { attainment }^{2}\end{array}$ & $\begin{array}{l}\text { Heterogeneity index. Groups classify shares of population } \\
\text { above } 25 \text { years. Categories are less than 9th grade; } 9 \text { th-12th } \\
\text { grade; high school graduate but no BA; BA or higher. }\end{array}$ & \\
\hline \%Comm & $\begin{array}{l}\text { Percent of CMA area with commercial establishment density } \\
\text { of } 70 \text { or more per square kilometer }\left(75^{\text {th }} \text { percentile in data). }\right.\end{array}$ & Spatial Insights, Inc. \\
\hline WRI & $\begin{array}{l}\text { Wharton Residential Urban Land Regulation Index developed } \\
\text { in Joseph Gyourko, Albert Saiz, and Anita Summers (2008). }\end{array}$ & Saiz (2010) \\
\hline
\end{tabular}

\footnotetext{
${ }^{1}$ The Herfindahl index is defined as $\sum_{j=1, \ldots J}\left(\left(\bar{q}_{j}-\bar{q}_{j-1}\right) / \bar{q}_{J}\right)^{2}$, where $\bar{q}_{j}$ denotes the allowance on tariff $j$ and $\bar{q}_{0}=0<\bar{q}_{1}<\cdots<\bar{q}_{J}$.

${ }^{2}$ The heterogeneity indexes for commuting time, household income, and educational attainment are defined as $1-\sum_{i}\left(\text { share of } \text { group }_{i}\right)^{2}$.
}

Digital $_{i m}$ equals one if firm $i$ adopted digital technology in the market by 1998 . Large $_{S c}$ and Small ${ }_{S c}$ indicate whether the firm operates a large or small network defined as more than fifteen and fewer than six markets, respectively. We also include provider fixed-effects. $\beta_{1}^{D}$ isolates the effect of entry on the incumbents' adoption choices.

Identifying the causal effect of entry on pricing and adoption is difficult since all three potentially reflect the attractiveness of a market in difficult-to-measure ways. If firms choose to build out less competitive markets first, this is likely similarly reflected in incumbents' pricing strategies or the attractiveness of implementing digital technology. For example, in markets with higher demand growth for cellular telephone usage we might expect faster entry and a greater chance of incumbents' upgrading to the digital technology, which allows for greater network capacity. This 
could introduce a spurious correlation between entry and adoption behavior that does not represent a causal effect. ${ }^{12}$

We control for the possibility of endogenous entry in two ways. First, we consider changes in the number of plans between 1996 and 1998, which removes any market-specific unobservable determinants of the incumbents' pricing strategies that are time-constant. Second, we instrument for the number of entrants in an auxiliary model using measures of geography and land-use regulations that affect the build-out delay across markets, but are uncorrelated with the incumbents' adoption and pricing decisions.

We specify the number of entrants, which ranges from 0 to 4 in the data, as an ordered probit model:

$$
\text { Entrants }_{m}= \begin{cases}0 & \text { if } f^{E}\left[\alpha^{E}, \beta^{E}, \mathbf{Z}_{m}^{E}\right]+\varepsilon_{m}^{E}<C_{1}^{E} \\ j & \text { if } C_{j}^{E}<f^{E}\left[\alpha^{E}, \beta^{E}, \mathbf{Z}_{m}^{E}\right]+\varepsilon_{m}^{E}<C_{j+1}^{E}, j=1,2,3 \\ 4 & \text { if } C_{4}^{E}<f^{E}\left[\alpha^{E}, \beta^{E}, \mathbf{Z}_{m}^{E}\right]+\varepsilon_{m}^{E},\end{cases}
$$

where the parameter $C_{j}^{E}$ implies a cutoff for the unobservable $\varepsilon_{m}^{E}$ between $j-1$ and $j$ entrants and:

$$
\begin{aligned}
f^{E}\left[\alpha^{E}, \beta^{E}, \mathbf{Z}_{m}^{E}\right] \equiv & \alpha^{E}+\beta_{1}^{E} \text { Pop }_{m}+\beta_{2}^{E} \text { Pop }_{m}^{2}+\beta_{3}^{E} \text { Area }_{m} \\
& +\beta_{4}^{E} W_{R} I_{m}+\beta_{5}^{E} \% \text { Comm }_{m}
\end{aligned}
$$

The market's potential subscriber base $\left(P o p_{m}\right)$ has an ambiguous effect on entry. A larger potential market attracts entry, while making it more difficult to satisfy build-out requirements. We include the market area $\left(\right.$ Area $\left._{m}\right)$ and two measures of local land use and its regulation to capture the difficulty of build out. Typically, the local municipal land-use office must approve new cell towers prior to their construction. Many local ordinances prohibit towers in residential zones, but allow them in industrial and commercial zones. Therefore, the stringency of local zoning laws directly affects the availability of appropriate tower sites in local markets and the cost and difficulty for a new entrant to build out a market. At the same time, local zoning laws should be uncorrelated with demand for cellular service or with incumbents' digital technology adoption decisions since incumbents upgrade by converting already existing towers, rather than having to site new towers.

Our first land-use measure is the 2005 Wharton Residential Urban Land Regulation Index $\left(W R I_{m}\right)$ created by Gyourko, Saiz, and Summers (2008). This index is a survey-based, standardized measure of the stringency of residential growth-control policies. We follow Saiz (2010) in aggregating the original municipality data to

\footnotetext{
${ }^{12}$ While we also control for a possible spurious correlation between entry and plan variety or placement, the theoretical mechanism underlying such correlation is less clear. The effect of market growth on the number of plans or their features is unaddressed in the theoretical literature, in which plan variety is determined by the heterogeneity of horizontal or vertical preferences or both but not by consumer density.
} 
the CMA level. CMAs with high WRI values have zoning regulations or project approval practices that limit new residential real estate development, possibly resulting in greater availability of candidate cell tower sites outside of constrained residential areas. This should ease market entry.

CMA-level commercial zoning data are unavailable. Instead, we use data obtained from Spatial Insights, Inc. on the number of establishments located in each block group to compute the share of a CMA's block groups that are likely zoned for mixed, commercial, or industrial use and therefore available as potential cell tower sites. To be conservative, we classify a block group as commercial if the density of establishments exceeds the 75 th percentile in the data (70 establishments per square kilometer). The variable \% Comm $_{m}$ measures the percent of the total CMA area containing commercial block groups. Higher values of $\% \mathrm{Comm}_{m}$ should be associated with easier market build-out and therefore entry.

Single-equation ordinary least squares (OLS) and ordered probit models of the number of entrants as a function of the explanatory variables in equation (6) confirm that entry is associated positively and significantly with both $W R I_{m}$ and $\%$ Comm $_{m}{ }^{13}$ The excluded instruments that affect neither the plan change nor the adoption decision are also jointly significant in explaining entry. For the OLS specification, the partial $F$-statistic for the hypothesis that the instruments do not enter the entry equation is 15.35 , while the $\chi^{2}$-statistic for the same hypothesis in the ordered probit model is 44.46 .

We assume that the plan change and adoption decision error terms can be decomposed into a market and a firm-(technology-)specific component with $\xi_{\text {imt }}^{P}=\varepsilon_{m}^{P}+$ $\eta_{\text {imt }}^{P}$ and $\xi_{\text {im }}^{D}=\varepsilon_{m}^{D}+\eta_{i m}^{D}$ where $\eta_{\text {imt }}^{P} \sim N(0,1)$ and $\eta_{i m}^{D} \sim N(0,1)$. Normalizing the variance of $\varepsilon_{m}^{E}$ to one, we allow for a flexible correlation structure between marketlevel errors:

$$
\left(\begin{array}{c}
\varepsilon_{m}^{D} \\
\varepsilon_{m}^{P} \\
\varepsilon_{m}^{E}
\end{array}\right) \sim N\left(\left(\begin{array}{c}
0 \\
0 \\
0
\end{array}\right),\left(\begin{array}{ccc}
\sigma_{D}^{2} & \sigma_{D P} & \sigma_{D E} \\
\sigma_{D P} & \sigma_{P}^{2} & \sigma_{P E} \\
\sigma_{D E} & \sigma_{P E} & 1
\end{array}\right)\right)
$$

$\varepsilon_{m}^{E}, \varepsilon_{m}^{D}$, and $\varepsilon_{m}^{P}$ are unobservable, market-specific factors that affect the entry, adoption, and plan change decisions, respectively, of all firms. The covariance terms allow for the kinds of correlations in the market-level unobservables discussed above. The Appendix contains details of the estimation approach.

Direct Effects.-The left panel of Table 4 shows the results of estimating the system-of-equations FIML specification for equations (1), (3), and (5). Entry has a significant effect on the change in the number of plans offered by both analog-only and mixed-technology providers. Mixed-technology incumbents introduce more digital plans and phase out more analog plans in markets with more entrants and

\footnotetext{
${ }^{13}$ The estimates under these two specifications are similar to those in Table 4.
} 
Table 4-Change in Number of Plans and Digital Technology Adoption by Cellular Incumbents, 1996-1998

\begin{tabular}{|c|c|c|c|c|c|}
\hline & \multicolumn{2}{|c|}{ FIML } & \multicolumn{3}{|c|}{ OLS } \\
\hline & Coefficient & $\begin{array}{l}\text { Standard } \\
\text { error }\end{array}$ & $\begin{array}{c}\text { Marginal } \\
\text { effect }\end{array}$ & Coefficient & $\begin{array}{l}\text { Standard } \\
\text { error }\end{array}$ \\
\hline \multicolumn{6}{|l|}{ Plan change equation } \\
\hline $\begin{array}{l}\text { Providers'Type of Technology, } 1998 \\
\text { Prov_Analog } \\
\text { Prov_Mixed } \\
\text { Plans_Digital }\end{array}$ & $\begin{array}{l}-0.733^{* *} \\
0.025 \\
2.205^{* *}\end{array}$ & $\begin{array}{l}0.363 \\
0.331 \\
0.240\end{array}$ & $\begin{array}{r}-1.066 \\
0.037 \\
3.208\end{array}$ & $\begin{array}{l}-1.422 \\
0.113 \\
3.016^{* *}\end{array}$ & $\begin{array}{l}1.097 \\
1.020 \\
0.362\end{array}$ \\
\hline $\begin{array}{l}\text { Market Characteristics } \\
\text { Prov_Analog } \times \text { Entrants } \\
\text { Prov_Digital } \times \text { Entrants } \\
\text { Prov_Mixed } \times \text { Plans_Analog } \times \text { Entrants } \\
\text { Prov_Mixed } \times \text { Plans_Digital } \times \text { Entrants } \\
\text { Population } \\
\text { Heterogeneity, Commuting Time } \\
\text { Heterogeneity, Household Income } \\
\text { Heterogeneity, Educational Attainment }\end{array}$ & $\begin{array}{l}0.126^{*} \\
0.037 \\
-0.294^{* *} \\
0.293^{* *} \\
3.5 \mathrm{E}-5 \\
-0.052^{* *} \\
-0.468^{* *} \\
-0.002\end{array}$ & $\begin{array}{l}0.096 \\
0.143 \\
0.098 \\
0.061 \\
0.003 \\
0.004 \\
0.003 \\
0.006\end{array}$ & $\begin{array}{l}0.184 \\
0.054 \\
-0.427 \\
0.426 \\
5.1 \mathrm{E}-5 \\
-0.075 \\
-0.680 \\
-0.002\end{array}$ & $\begin{array}{l}0.498^{* *} \\
0.268 \\
-0.442^{* *} \\
0.484 * * \\
0.004 \\
-0.104 \\
-0.720 * * \\
-0.015\end{array}$ & $\begin{array}{l}0.222 \\
0.429 \\
0.200 \\
0.083 \\
0.010 \\
0.164 \\
0.323 \\
0.068\end{array}$ \\
\hline Digital adoption decision equation & & & & & \\
\hline $\begin{array}{l}\text { Market characteristics } \\
\text { Entrants } \\
\% \text { with BA } \\
\text { Commuting time } \\
\text { Population } \\
\text { Household income }\end{array}$ & $\begin{array}{l}0.566^{* *} \\
-0.039^{* *} \\
0.019 \\
0.038^{* *} \\
0.033^{* *}\end{array}$ & $\begin{array}{l}0.207 \\
0.020 \\
0.026 \\
0.022 \\
0.017\end{array}$ & $\begin{array}{r}0.108 \\
-0.007 \\
0.004 \\
0.007 \\
0.006\end{array}$ & $\begin{array}{l}0.096^{*} \\
-0.008 \\
0.006 \\
0.004^{* *} \\
0.011^{* *}\end{array}$ & $\begin{array}{l}0.052 \\
0.010 \\
0.016 \\
0.002 \\
0.005\end{array}$ \\
\hline $\begin{array}{l}\text { Provider characteristics } \\
\text { Large potential network } \\
\text { Small potential network }\end{array}$ & $\begin{array}{l}2.818^{* *} \\
2.065^{* *}\end{array}$ & $\begin{array}{l}0.496 \\
0.357\end{array}$ & $\begin{array}{l}0.538 \\
0.394\end{array}$ & $\begin{array}{r}0.190^{* *} \\
-0.263^{* *}\end{array}$ & $\begin{array}{l}0.037 \\
0.104\end{array}$ \\
\hline $\begin{array}{l}\text { Adjusted } R^{2} \text { (plan change, adoption) } \\
n \text { (plan change, adoption) } \\
\text { Log-likelihood (FIML) }\end{array}$ & $\begin{array}{c}306 \\
-757.643\end{array}$ & & & $\begin{array}{c}(0.739,0.388) \\
(306,193)\end{array}$ & \\
\hline
\end{tabular}

Notes: Provider fixed effects included in plan change and digital adoption decision equations. Standard errors clustered at the provider level based on 50 bootstrapped samples for FIML estimates. For the FIML specification, the estimated coefficients of the entry equation with the corresponding standard errors in parentheses are:

$$
\text { ENTRANTS }=\underset{(0.0210)}{0.137 P O P}-\underset{(0.0002)}{0.001 P O P^{2}}+\underset{(0.0162)}{0.055 A R E A}+\underset{(0.0196)}{0.087 \% \text { COMM }}+\underset{(0.0987)}{0.357 \mathrm{WRI}}+\varepsilon^{E},
$$

with estimated covariances $\left\{\sigma_{D E}, \sigma_{E P}, \sigma_{D P}\right\}$ and variances $\left\{\sigma_{D}^{2}, \sigma_{P}^{2}\right\}$ of $\{0.181,-0.200,-0.256\}$ and $\{0.488,0.166\}$.

** Significant at the 5 percent level.

*Significant at the 10 percent level.

both effects are highly significant. These incumbents introduce 0.43 digital plans and remove 0.43 analog plans for each additional entrant. This aspect of our results is complementary to work by Ron Borzekowski, Raphael Thomadsen, and Charles Taragin (2009) who find that direct-mail-marketing firms offer a larger number of distinctly-priced selection criteria, and thus price-discriminate more finely, in markets with more competitors. Incumbents who remain with the analog technology introduce 0.18 additional plans for each additional entrant. These effects are economically significant given means of 5.89 plans and 2.16 entrants in a market. The effect of entry on digital-only incumbents is positive but insignificant, perhaps because there are only fifteen observations to identify this effect. Of the demand 
covariates, a one standard deviation increase decreases the number of plans in a market by 0.08 plans for commuting time and by 0.16 plans for income.

The system of equations is identified without instruments because of the nonlinearities of the ordered probit equation for entry. Since identification derives in part from the functional form assumptions for the errors, we also estimate an OLS model, displayed in the right panel of Table 4 . The three significant entry effects under OLS are mostly in line with the corresponding marginal effects from the FIML results: an additional entrant in a market is associated with a decrease of 0.44 analog plans and an increase of 0.48 digital plans for a mixed-technology incumbent. The OLS estimates imply that analog-only incumbents introduce 0.50 plans for each additional entrant, while the results for digital-technology providers remain insignificant. Of the demand heterogeneity variables, only income heterogeneity has a significant negative effect on the change in the number of calling plans.

Indirect Effects.-Entry also has a significant indirect effect on firms' pricing schedules by increasing the likelihood that an incumbent will transition to the digital technology, thereby causing it to reduce the size of or phase out its analog plan family while introducing a larger family of digital plans. The lower panels of Table 4 display the FIML and OLS results for the adoption equation. Entry positively affects adoption, with each additional entrant increasing the probability of adoption by 10.80 and 9.59 percentage points in the FIML and OLS cases, respectively.

The FIML results indicate a U-shaped effect of firm scope on digital adoption, with large- and small-scope firms being more likely to adopt than medium-scope firms. Large-scope firms may benefit from cost savings associated with learning-bydoing or quantity discounts in equipment purchases. Small-scope firms, which are likely to attract consumers who travel less, are less affected by incompatibility of different digital technologies outside their locale, and therefore have greater demandside incentives to adopt earlier. Adoption is higher in more populous, wealthier, and less highly educated markets.

Comparing Direct and Indirect Effects.-Using the FIML results, we can compare the relative importance of the direct and indirect effects in moving from having no new entrants to having an average level of entry ( 2.16 firms). This change directly induces mixed-technology incumbents to phase out an additional 0.92 analog and introduce an additional 0.92 digital plans. The incumbent's probability of adopting the digital technology also increases by 16.35 percentage points. Incumbent firms that transition from analog-only to mixed provider in turn introduce 3.24 digital plans and an additional 1.10 analog plans. Therefore, in expectation, entry indirectly causes a firm to introduce an additional 0.53 digital and 0.18 analog plans. ${ }^{14}$ This represents a substantial indirect effect on marketing the new technology and highlights the role of technology choice as a second avenue through which market structure affects firms' nonlinear pricing strategies.

\footnotetext{
${ }^{14} \mathrm{~A}$ similar calculation for transition to a digital-only provider yields a direct effect of 0.12 and an expected indirect effect of 0.52 plan introductions.
} 
Our technology adoption results are of independent interest as they are consistent with theoretical predictions. In the Appendix, we consider a model of strategic technology adoption in the spirit of Fudenberg and Tirole (1986). Anticipating future entry by PCS firms, the cellular incumbent chooses the optimal time to introduce digital service, which we model as a product innovation. In contrast to Fudenberg and Tirole (1986), we focus on entrants who have pre-committed to digital technology, eliminating a strategic deterrence motive in the incumbent's decision. The model predicts that the incumbent's adoption timing hinges on the sensitivity of its post-entry profits to its decision. If increased competition from additional firms dramatically reduces the incumbent's profits from the old technology relative to those from the new, it is more likely to adopt before entry occurs. Our empirical results thus suggest that the onset of PCS competition has a greater adverse effect on incumbents' profits from analog service than on those from digital offerings. This is probably because of the fast consumer uptake of digital service discussed earlier and is likely the case in information and communications services industries more broadly. In these industries, revenues from new technologies tend to quickly overtake those from old, and the price of old technologies is more sensitive to increased competition than the price of new.

These results are also consistent with those of Barton H. Hamilton and Brian McManus (2005) that firms in competitive markets are more likely to have adopted a new technology earlier than those in monopoly markets. Together our papers provide a complementary picture of the role of technology adoption in firm behavior. While we focus on how technology adoption affects adopters' pricing, their work focuses on how it affects adopters' market shares and ability to deter entry. ${ }^{15}$

\section{B. Effect on Plan Placement}

Our results so far demonstrate that entry led to finer price discrimination as measured by plan family size. Since the size on its own does not provide information about which types of consumers are targeted with different plans, we now test the effect of entry on calling plan placement across the usage spectrum. We find that, with more entry, firms spread their plans more evenly over the usage spectrum for most plan types. This is consistent with business-stealing overpowering the firm's incentive to differentiate under increased competition. This result reinforces the plan change results by confirming that they are not due to counting very similar plans as distinct.

To measure plan placement and clustering, we use a Herfindahl index based on the share of minutes "allocated" to each plan, which, once normalized, is comparable across plan families. While it would be useful to compare the plan variety observed in our data with that predicted by theory, this is not possible given the current theoretical literature. Instead, we rely on this descriptive measure of plan placement across markets in the same industry so that we can relate it to market

\footnotetext{
${ }^{15}$ Hannan and McDowell (1984), Karshenas and Stoneman (1993), Sharon Oster (1982), and Nancy L. Rose and Paul L. Joskow (1990) investigate the effect of firm characteristics on adoption speed. Apart from firms' geographic scope, we cannot examine this question because firms' subscriber bases, revenues, and network sizes by market are unavailable.
} 
structure while controlling for the possibility that placement might depend on heterogeneous consumer preferences across markets.

We assume that the total allocable minutes within a plan family equals the largest allowance on any plan within the family. ${ }^{16}$ We define the minutes allocated to a plan as the difference between the plan's allowance and the closest smaller allowance in the plan family (or zero for the first plan). For example, if a plan family includes two plans with allowances of 300 and 500 minutes, the Herfindahl index is $((500-300) / 500)^{2}+((300-0) / 500)^{2}=13 / 25$. For a plan family with $n$ plans, the Herfindahl index ranges from a value of $1 / n$ if all plans are equally spaced to a value of 1 if all plans are identical.

To make the Herfindahl index comparable across different-sized plan families, we normalize it by dividing by the Herfindahl that results from equal spacing of plans $(1 / n)$. In our example above, the normalized Herfindahl is $(13 / 25) /$ $(1 / 2)=(26 / 25)$. For a plan family with $n$ plans, the normalized Herfindahl ranges from one, if all plans are equally spaced, to $n$, if all plans are identical. The top panel of Table 5 provides summary statistics, using both entrants' and incumbents' 1998 offerings, which increases the number of observations to 521 plan families.

Econometric Model.-We use a setup similar to the plan change model and specify the firms' choices of plan placement as:

$$
\begin{aligned}
\text { NormHHI }_{i m t}= & \alpha^{H}+\beta_{1}^{H} \text { Prov_Tech }_{i m}+\beta_{2}^{H} \text { Plan_Type }_{i m} \\
& +\beta_{3}^{H}\left(\text { Prov_Tech }_{i m}\right)\left(\text { Plan_Type }_{i m}\right)\left(\text { Entrants }_{m}\right) \\
& +\beta_{\geq 4}^{H} \mathbf{X}_{i m}^{H}+\xi_{i m t}^{H} \\
\equiv & f^{H}\left[\alpha^{H}, \beta^{H}, \mathbf{Z}_{i m t}^{H}\right]+\xi_{i m t}^{H},
\end{aligned}
$$

where NormHHI $_{\text {imt }}$ is the normalized Herfindahl index of plan placement in 1998. We employ levels instead of heterogeneity measures for the demographic variables to capture how overall demand affects firms' choices of plan spacing. We again estimate the system of equations (3), (5), and (8) using FIML, accounting for the simultaneous choice of technology adoption and market entry. The Appendix describes the adjustments made to the estimation procedure to reflect the continuous nature of the normalized Herfindahl measure that replaces the discrete plan change variable. ${ }^{17}$

Direct and Indirect Effects.-Competition has a significant and negative direct effect on the normalized Herfindahl index for the majority of plan family types. These

\footnotetext{
${ }^{16}$ As a robustness check, we replicate our results using as a measure of allocable minutes the number of minutes for which a particular plan represents the cost-minimizing option in the plan family. The disadvantage of this measure relative to the allowance-based measure is that it requires an assumption about consumers' maximum usage. To check the sensitivity of the results to this assumption, we estimate assuming a maximum usage of either 1,000 or 2,000 minutes. The results are similar to those in Table 6 in both magnitude and significance of the coefficients regardless of the assumption of maximum usage.

${ }^{17}$ We do not include entrants' choice of technology in estimating equation (3) since entrants pre-commit to the digital technology.
} 
Table 5-Summary Statistics, Allowance-Based Plan Placement Measures, Incumbents' and ENTRANTS' 1998 Plans

\begin{tabular}{lccccc}
\hline \hline & Mean & SD & Minimum & Maximum & Observations \\
\hline $\begin{array}{l}\text { Full menu of plans } \\
\text { Herfindahl, families with 5-7 plans }\end{array}$ & 0.358 & 0.108 & 0.193 & 0.789 & 335 \\
$\begin{array}{c}\text { Normalized Herfindahl, all plan } \\
\text { families }\end{array}$ & 1.936 & 0.708 & 1.000 & 5.868 & 521 \\
$\begin{array}{c}\text { "High-usage" and "low-usage" plans } \\
\quad \begin{array}{l}\text { Share of plans above median, } \\
\text { all plan families }\end{array}\end{array}$ & 0.553 & 0.214 & 0.000 & 1.000 & 521 \\
$\begin{array}{c}\text { Normalized Herfindahl above } \\
\text { median, all plan families } \\
\text { Normalized Herfindahl below } \\
\text { median, all plan families }\end{array}$ & 1.325 & 0.390 & 1.000 & 3.021 & 504 \\
\hline
\end{tabular}

results, shown in the left-hand columns of Table 6 , are also economically significant. As a share of the mean across all plan families, an additional competitor decreases the normalized Herfindahl by 9.40 percent for analog-only providers, 6.03 percent for digital-only, and 4.83 percent for analog plans offered by mixed-technology providers. The one exception is digital offerings by mixed-technology providers which become more clustered in response to additional competition: an additional competitor increases the normalized Herfindahl by 5.81 percent. In general, increased competition leads firms to spread plans more evenly across the usage spectrum, increasing plan variety.

The indirect effect of competition leads firms to increase plan variety for all plan types. For a given number of entrants, the digital plan families offered by mixed or digital-only providers exhibit less clustering than the analog offerings. Therefore, by raising the probability of digital adoption, additional competition results in firms offering greater plan variety. For providers that transition from analog-only to offering both technologies, the normalized Herfindahl index declines by 0.25 (12.69 percent of the mean) for analog plan families and by 2.29 (118.36 percent of the mean) for digital. For these plan family types, the indirect effects reinforce the direct effects. For a provider that transitions to digital-only offerings, the decrease in the normalized Herfindahl is 1.31 (67.84 percent of the mean), offsetting the direct effects of competition.

Evaluated at the mean level of entry, the direct effects are larger in absolute magnitude than the indirect effects for both mixed and digital-only providers. For mixed providers, the average increase in the number of competitors entails a direct reduction of 0.20 in the normalized Herfindahl index for analog plan families and a direct increase of 0.24 for digital plan families. Accounting for the increased likelihood of digital adoption at the mean level of entry, indirect effects are negligible for analog plan families and a decrease of 0.07 in the normalized Herfindahl for digital families. A similar calculation for transition to a digital-only provider yields a direct effect of -0.25 and an expected indirect effect of -0.04 .

Robustness.-To test the robustness of our results to the plan placement measure, we re-estimate using the non-normalized Herfindahl index and restricting the sample 
Table 6-Placement of Incumbents' and Entrants' 1998 Pricing Plans Based on Allowance Levels: FIML ESTIMATION

\begin{tabular}{|c|c|c|c|c|}
\hline & \multicolumn{2}{|c|}{$\begin{array}{l}\text { Normalized Herfindahl all } 1998 \\
\text { plan families }\end{array}$} & \multicolumn{2}{|c|}{$\begin{array}{l}\text { Herfindahl, } 1998 \text { plan families } \\
\text { with 5-7 plans }\end{array}$} \\
\hline & Coefficient & $\begin{array}{l}\text { Standard } \\
\text { error }\end{array}$ & Coefficient & $\begin{array}{l}\text { Standard } \\
\text { error }\end{array}$ \\
\hline \multicolumn{5}{|l|}{ Provider and plan characteristics } \\
\hline Prov_Analog & $-0.732 * *$ & 0.2627 & $0.086^{*}$ & 0.0661 \\
\hline Prov_Mixed & $-0.978 * *$ & 0.2154 & $-0.131 * *$ & 0.0516 \\
\hline Plans_Digital & $-1.313^{* *}$ & 0.1715 & -0.014 & 0.0365 \\
\hline Entrant_YN & $0.355^{* *}$ & 0.1456 & 0.034 & 0.0340 \\
\hline \multicolumn{5}{|l|}{ Market structures (IT) } \\
\hline Prov_Analog $\times$ Competitors & $-0.182 * *$ & 0.0687 & $-0.043^{* *}$ & 0.0207 \\
\hline Prov Digital $\times$ Competitors & $-0.117 * *$ & 0.0519 & -0.012 & 0.0161 \\
\hline Prov Mixed $\times$ Plans Analog $\times$ Competitors & $-0.093 * *$ & 0.0568 & 0.013 & 0.0184 \\
\hline Prov_Mixed $\times$ Plans_Digital $\times$ Competitors & $0.113^{* *}$ & 0.0544 & 0.008 & 0.0174 \\
\hline \multicolumn{5}{|l|}{ Market characteristics } \\
\hline$\%$ with BA & -0.023 & 0.0239 & $-0.007 *$ & 0.0052 \\
\hline Commuting time & $-0.328 * *$ & 0.0796 & -0.013 & 0.0127 \\
\hline Population & $0.010^{* *}$ & 0.0020 & $0.001 *$ & 0,0005 \\
\hline Household income & -0.042 & 0.0588 & $-0.050 * *$ & 0.0155 \\
\hline $\mathrm{SD}, \eta^{\text {Herf }}$ & $0.551^{* *}$ & 0.0211 & $0.085^{* *}$ & 0.0042 \\
\hline Log-likelihood & -664.68 & & 178.71 & \\
\hline Observations & 521 & & 335 & \\
\hline
\end{tabular}

Notes: Provider fixed-effects included in plan variety and digital adoption decision equations. Provider-level clustered standard errors based on 50 bootstrapped samples. The estimated coefficients of the two auxiliary equations, with the corresponding bootstrap standard errors in parentheses, are for Specification I:

and for Specification II:

$$
\begin{aligned}
& \text { ENTRANTS }=\underset{(0.0215)}{0.158} \underset{(0.0002)}{0.002 P O P^{2}}+\underset{(0.0619)}{0.072 A R E A}+\underset{(0.0375)}{0.100 \% \text { COMM }}+\underset{(0.1063)}{0.386 \text { WRI }}+\varepsilon^{E} \\
& A D O P T I O N=0.157 \underset{(0.1031)}{E N T R A N T S}-\underset{(0.0219)}{0.033} \text { BAPLUS }+0.029 \underset{(0.0285)}{\operatorname{COMMUTE}}+\underset{(0.0163)}{0.048} \text { POP }
\end{aligned}
$$

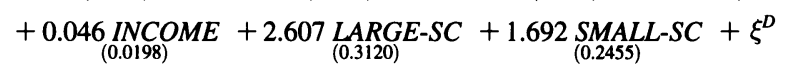

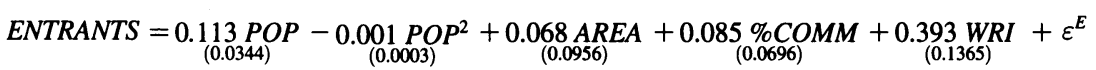

$$
\begin{aligned}
& A D O P T I O N=0.258 \underset{(0.2359)}{E N T R A N T S}-\underset{(0.0465)}{0.017 \text { BAPLUS }}+0.001 \underset{(0.0630)}{\text { COMMUTE }}+\underset{(0.0304)}{0.056} \text { POP }
\end{aligned}
$$

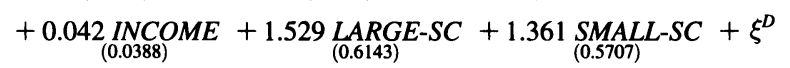

The variables in the entrant equation are defined in Table 4. The estimated covariances $\left\{\sigma_{D E}, \sigma_{E P}, \sigma_{D P}\right\}$ are $\{0.003,0.055,0.001\}$ and $\{-0.002,0.105,-0.133\}$ and the estimated variances $\left\{\sigma_{D}^{2}, \sigma_{P}^{2}\right\}$ are $\{0.005,0.109\}$ and $\{0.249,0.153\}$ for Specifications I and II, respectively.

** Significant at the 5 percent level.

*Significant at the 10 percent level.

to plan families with five to seven plans. This reduces the number of observations to 335. Summary statistics are in the top panel of Table 5 and the results are shown in the right-hand columns of Table 6 . The results for plan families in single-technology offerings are directionally consistent with those using the full sample, although not as significant perhaps due to the reduced number of observations. For this sub-sample, the average Herfindahl in markets without entry is equivalent to 2.79 equally spaced plans. The average level of entry increases this to 3.77 for analog plan 
families. The results in mixed-technology offerings and for digital-only providers are not significant, possibly because the majority of the lost observations are for these. ${ }^{18}$

\section{Heterogeneous Effects on Consumers}

Thus far we have found that entry increases the number of plans offered by incumbent firms and typically spreads these plans more evenly across the usage spectrum. We now test whether an increase in competition has a differential effect on high-versus low-valuation consumers. We find that firms respond to increased competition by increasing the number of plans targeted at customers whom their technologies best serve.

To test the relative effect on high-valuation consumers, we classify calling plans into high- and low-usage. We designate a calling plan as "high-usage" if its allowance is greater than 180 , the median allowance across all plans in our sample. We again include both entrants and incumbents to increase the number of observations and focus on levels since all entrants had zero plans in 1996. Summary statistics for three measures of plan mix (share of high-usage plans offered and the normalized Herfindahl indices among high-usage or low-usage plans) are displayed in the bottom panel of Table 5. As in our other models, we specify the firms' choices of plan mix as a function of the provider's technology type, the plan family's technology, and entry effects that vary by provider type and technology, and market demographics. We use FIML to jointly estimate the determinants of the plan mix together with the determinants of adoption (equation 3 ) and of aggregate entry (equation 5).

Relative Prevalence of High-Usage Plans.-Our primary measure is the share of high-usage plans in a plan family. We find that the share of high-usage plans increases significantly with the number of competitors for digital-only providers but decreases for mixed-technology providers. The results are shown in the left-hand columns of Table 7. The average share of high-usage plans is 55.30 percent. An additional competitor increases the share by 1.75 for digital-only providers, which includes both new PCS entrants and incumbents who fully replaced analog with digital offerings. This is a large effect given that the number of competitors ranges from two to six. For mixed-technology providers, the share is reduced by 2.25 for analog offerings and 3.42 for digital offerings.

These results suggest that increased competition induces firms to use price discrimination differentially depending on their technology adoption choice. Incumbents and new entrants who use digital transmission technologies exclusively exploit the benefits of their increased network capacity by targeting high-valuation users. Providers that continue to offer at least some service on the more-constrained analog technology instead respond to more entry by increasing their share of plans targeted at low-valuation customers. Competition thus results in firms tailoring

\footnotetext{
${ }^{18}$ To ensure that our results are not sensitive to our specific choice of clustering measure, we re-estimated using a modified L-function index developed by Eric Marcon and Florence Puech (2003) for use in measuring industry agglomeration. We adapted the L-function index to our one-dimensional, linear setting rather than the circular setting needed in industry agglomeration. The results using the L-function index are qualitatively similar, and generally stronger, than the estimates using the Herfindahl index.
} 
Table 7-Placement of High-Usage Plans, Incumbents' and Entrants' 1998 Pricing Plans: FiML Estimation

\begin{tabular}{|c|c|c|c|c|c|c|}
\hline & \multicolumn{2}{|c|}{$\begin{array}{l}\text { Share of plans } \\
\text { above median }\end{array}$} & \multicolumn{2}{|c|}{$\begin{array}{c}\text { Normalized Herfindahl } \\
\text { above median }\end{array}$} & \multicolumn{2}{|c|}{$\begin{array}{c}\text { Normalized Herfindahl } \\
\text { below median }\end{array}$} \\
\hline & Coefficient & $\begin{array}{l}\text { Standard } \\
\text { error }\end{array}$ & Coefficient & $\begin{array}{l}\text { Standard } \\
\text { error }\end{array}$ & Coefficient & $\begin{array}{c}\text { Standard } \\
\text { error }\end{array}$ \\
\hline $\begin{array}{l}\text { Provider and plan characteristics } \\
\text { Prov_Analog } \\
\text { Prov_Mixed } \\
\text { Plans_Digital } \\
\text { Entrant_YN }\end{array}$ & $\begin{array}{r}0.468^{* * *} \\
0.206^{* * *} \\
0.377^{* * *} \\
-0.195^{* * *}\end{array}$ & $\begin{array}{l}0.087 \\
0.055 \\
0.055 \\
0.025\end{array}$ & $\begin{array}{c}0.099 \\
-0.082 \\
-0.173^{*} \\
-0.075^{*}\end{array}$ & $\begin{array}{l}0.171 \\
0.129 \\
0.117 \\
0.051\end{array}$ & $\begin{array}{c}-0.265^{*} \\
-0.353^{* *} \\
-0.408^{* *} \\
0.598^{* * *}\end{array}$ & $\begin{array}{l}0.202 \\
0.189 \\
0.209 \\
0.131\end{array}$ \\
\hline $\begin{array}{l}\text { Market structure } \\
\text { Prov_Analog } \times \text { Competitors } \\
\text { Prov_Digital Competitors } \\
\text { Prov_Mixed } \times \text { Plans_ } \\
\quad \text { Analog } \times \text { Competitors }\end{array}$ & $\begin{array}{c}-0.013 \\
0.017^{*} \\
-0.025^{* *}\end{array}$ & $\begin{array}{l}0.015 \\
0.012 \\
0.013\end{array}$ & $\begin{array}{l}-0.140^{* * *} \\
-0.042^{* *} \\
-0.088^{* * *}\end{array}$ & $\begin{array}{l}0.028 \\
0.020 \\
0.025\end{array}$ & $\begin{array}{c}0.008 \\
-0.095^{* * *} \\
0.042\end{array}$ & $\begin{array}{l}0.036 \\
0.030 \\
0.044\end{array}$ \\
\hline $\begin{array}{l}\text { Prov_Mixed } \times \text { Plans_ } \\
\text { Digital } \times \text { Competitors }\end{array}$ & $-0.034 * *$ & 0.013 & -0.007 & 0.023 & 0.016 & 0.039 \\
\hline $\begin{array}{l}\text { Market characteristics } \\
\% \text { with BA } \\
\text { Commuting time } \\
\text { Population } \\
\text { Household income } \\
\text { SD, } \eta^{Y}\end{array}$ & $\begin{array}{l}-0.005^{* * *} \\
0.003^{* *} \\
3.4 \mathrm{E}-04 \\
0.004^{* *} \\
0.143^{* * *}\end{array}$ & $\begin{array}{l}0.001 \\
0.002 \\
0.001 \\
0.002 \\
0.004\end{array}$ & $\begin{array}{r}0.011^{* * *} \\
-0.002 \\
6.5 \mathrm{E}-05 \\
-0.008 * * * \\
0.321 * * *\end{array}$ & $\begin{array}{l}0.003 \\
0.005 \\
0.001 \\
0.002 \\
0.009\end{array}$ & $\begin{array}{l}0.003 \\
0.006^{* *} \\
-0.001^{*} \\
0.004 \\
0.431^{* * *}\end{array}$ & $\begin{array}{l}0.003 \\
0.004 \\
0.001 \\
0.005 \\
0.024\end{array}$ \\
\hline $\begin{array}{l}\text { Log-likelihood } \\
\text { Observations }\end{array}$ & $\begin{array}{r}87 . \\
52\end{array}$ & & $\begin{array}{r}-335 \\
50\end{array}$ & .35 & $\begin{array}{r}-47 \\
48\end{array}$ & \\
\hline
\end{tabular}

Notes: Provider fixed-effects included in plan variety and digital adoption decision equations. Provider-level clustered standard errors based on 50 bootstrapped samples. The estimated coefficients of the auxiliary equations with the corresponding bootstrap standard errors in parentheses are for Specification I:

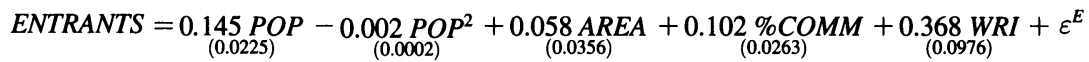

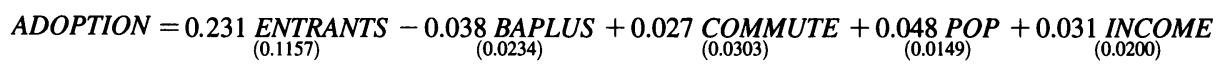

$$
\begin{aligned}
& +2.264 \underset{(0.4054)}{L A R E-S C}+1.735 \underset{(0.4544)}{S M A L L-S C}+\xi^{D},
\end{aligned}
$$

for Specification II:

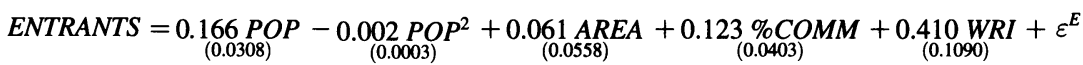

$$
\begin{aligned}
& A D O P T I O N=0.161 \underset{(0.1966)}{E N T R A N T S}-\underset{(0.0264)}{0.035 \text { BAPLUS }}+0.030 \underset{(0.0454)}{\operatorname{COMMUTE}}+\underset{(0.0266)}{0.051} P O P+\underset{(0.0229)}{0.048 \text { INCOME }} \\
& +2.788 \underset{(0.7410)}{\operatorname{LARGE} E S C}+2.462 \underset{(0.5434)}{\operatorname{SMALL}}-S C+\xi^{D},
\end{aligned}
$$

and for Specification III:

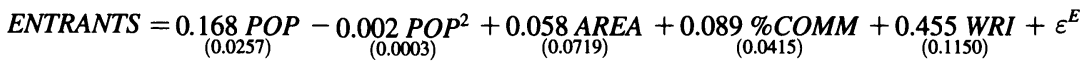

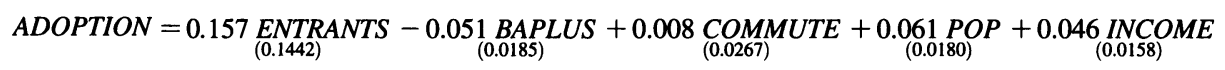

$$
\begin{aligned}
& +2.419 \underset{(0.5509)}{L A R G E-S C}+1.956 \underset{(0.4995)}{\operatorname{SMALL} L S C}+\xi^{D} .
\end{aligned}
$$

The variables are defined in Table 4 . The estimated covariances $\left\{\sigma_{D E}, \sigma_{E P}, \sigma_{D P}\right\}$ are $\{-0.027,0.123,0.008\},\{0.091$, $-0.038,-0.036\}$, and $\{0.020,0.103,-0.014\}$ for Specifications I-III. The estimated variances $\left\{\sigma_{D}^{2}, \sigma_{P}^{2}\right\}$ are $\{0.082,0.098\},\{0.049,0.076\}$, and $\{0.024,0.045\}$ for Specifications I-III.

$* * *$ Significant at the 1 percent level.

** Significant at the 5 percent level.

*Significant at the 10 percent level. 
their offerings to the customer group whose demand is best served by their chosen technology.

Entry also has a significant indirect effect on the share of high-usage plans. For a mixed provider, the share of digital plans above the median is $\mathbf{5 8 . 3 4}$ percent and for a digital-only provider 37.70 percent. This compares to 46.85 percent for analog-only plan families. Therefore, transitioning to a mixed provider indirectly increases the share of plans above the median while transitioning to a digital-only provider decreases it.

We can also compare the relative importance of the direct and indirect effects for a mixed-technology provider at the average level of entry. Entry directly decreases the share of plans above the median by 5.45 percentage points for analog and by 7.38 percentage points for digital families. Incorporating the predicted probability of adoption at the mean level of competition, the indirect effects decrease the share of analog plans by 2.37 percentage points and increase the share of digital plans by 5.28 percentage points. ${ }^{19}$

Robustness.-To ensure that the plans targeting high-(low-)valuation consumers are distinct, we also employ a Herfindahl index, normalizing it by the index if all plans above (below) the median were equally spaced. For plans above the median, we base the Herfindahl index on the spectrum of minutes from the allowance just below the median (180 minutes) to the largest allowance within the plan family. For example, consider a plan family with plans having allowances of 50, 100, 200, and 500 minutes. There are two plans with above-median allowances and (500 $100)$ minutes, or 400 minutes, of allocable usage. The resulting Herfindahl index is $((500-200) / 400)^{2}+((200-100) / 400)^{2}=5 / 8$. To normalize the Herfindahl we divide by $1 / 2$, the Herfindahl if the two plans above the median were equally spaced, to obtain a normalized Herfindahl of $5 / 4$. Theoretically, this measure ranges from a minimum of 1 when high-usage plans are equally spaced, to $n$, when all $n$ high-usage plans are identical. ${ }^{20}$ In our data, it ranges from 1.00 to 3.02. Similarly, for plans below the median we base the Herfindahl index on the spectrum of minutes from zero to the allowance just above the median (180 minutes), which ranges from 1.00 to 5.15 in our data. The econometric specification is that given by equation (8), using the normalized Herfindahl indeces for high and low usage plans in place of the original measure for the full usage spectrum.

The results using the normalized Herfindahl above the median are shown in the middle columns of Table 7. Entry has a negative and significant direct effect for all plan family types except digital-only. Relative to the average normalized Herfindahl above the median across all plan families (1.33), each additional competitor reduces the normalized Herfindahl by 3.14 to 10.59 percent, depending on the plan family and provider type. The indirect effect of competition is negative but not economically significant. We thus find that high-usage plans are more distinct with more entry.

\footnotetext{
${ }^{19} \mathrm{~A}$ similar calculation for transition to a digital-only provider yields a direct increase of 3.78 and an expected indirect increase of 3.41 percentage points.

${ }^{20}$ The Herfindahl in the numerator is undefined when there are no high- (low-) usage plans. This accounts for the seventeen (thirty-three) observations we lose when using these measures.
} 
The results for the normalized HHI below the median are shown in the right-hand columns of Table 7. Entry has a negative and significant direct effect for digital-only plan families. Each additional competitor reduces the normalized Herfindahl by 5.56 percent of the normalized Herfindahl below the median across all plan families (1.71). The direct effects for other plan types are not significant. The indirect effects of competition are statistically significant but economically small. Incorporating the predicted probability of adoption at the mean level of entry, the indirect effect reduces the normalized Herfindahl below the median by 1.97 percent for mixed-digital, 1.06 percent for digital-only providers, and 0.23 percent for analog-only providers as a percentage of the average normalized Herfindahl below the median (1.71). We thus find that low-usage plans are more distinct with more entry for digital-only providers and slightly more distinct with more entry for mixed-digital providers.

\section{Effect on Price Levels}

Since competition significantly alters the nonlinear pricing practices of cellular firms this raises the question of how price levels are affected overall and across different consumers. We follow the approach of Busse and Rysman (BR) (2005) to assess the effect of competition on quantity discounting. ${ }^{21}$ This is equivalent to measuring the response in price-cost ratios to changes in competition if, as is likely in our setting, the marginal cost of providing service to low- versus high-valuation customers does not vary with competition. Overall, we find that increased competition results in greater price reductions for high-usage consumers.

Econometric Model.-BR suggest testing whether the price schedule's curvature changes with the number of competitors. We follow their approach in specifying the $\log$ price charged by provider $i$ for $q_{j}$ minutes of service on technology $t, P_{i j m t}$, as:

$$
\ln \left(P_{i j m t}\right)=\alpha_{i m t}+\beta_{i m t} \ln \left(q_{j}\right)+\varepsilon_{i j m t},
$$

where $\alpha_{\text {imt }}$ captures differences in cost or demand levels across providers and markets and $\beta_{i m t}$ the curvature of the price schedule. A value of one for $\beta_{i m t}$ corresponds to linear pricing, $\beta_{i m t}<1$ to quantity discounting, and $\beta_{i m t}>1$ to quantity premia.

To estimate equation (9), we construct a grid of usage levels in ten-minute increments. For each plan family, we compute the minimum total price at each grid point across all calling plans in the family, thus constructing the lower envelope of prices. The underlying assumption, as in Miravete and Röller (2004), is that consumers choose the optimal plan for their usage. We bound the usage grid at 1,000 minutes. Individual-level usage data for 1999 and 2000 obtained from TNS Telecoms indicate a usage level of 985 minutes for the $99^{\text {th }}$ percentile of consumers. Since our data cover an earlier period, a cutoff of 1,000 minutes represents a reasonable estimate for maximum usage. Our results are robust to using a 2,000-minute cutoff.

\footnotetext{
${ }^{21}$ In related work, McManus (2007) provides empirical evidence for the "no distortion at the top" prediction of theoretical models of nonlinear pricing.
} 
TABle 8-Distribution of Estimated Curvature of InCUMBEnts' AND ENTRANTS' 1998 PRICING SCHEDULES

\begin{tabular}{lccc}
\hline \hline & $\begin{array}{c}\text { Analog plans, } \\
\text { incumbents }\end{array}$ & $\begin{array}{c}\text { Digital plans, } \\
\text { incumbents }\end{array}$ & Entrants \\
\hline Mean & 0.627 & 0.444 & 0.486 \\
SD & 0.093 & 0.109 & 0.099 \\
Min & 0.402 & 0.167 & 0.197 \\
Max & 0.920 & 0.837 & 0.844 \\
Percentiles: & & & \\
5 percent & 0.465 & 0.260 & 0.282 \\
25 percent & 0.560 & 0.404 & 0.438 \\
50 percent & 0.640 & 0.432 & 0.483 \\
75 percent & 0.689 & 0.492 & 0.552 \\
95 percent & 0.774 & 0.653 & 0.616 \\
Average adjusted $R^{2}$ & & & \\
Observations & 0.946 & 0.872 & 0.903 \\
& 178 & 128 & 215 \\
\hline
\end{tabular}

We use a two-stage procedure. We first obtain the price schedule parameters $\alpha$ and $\beta$ for every technology-provider-market combination by separately estimating equation (9) for each plan family using OLS. This generates a distribution of estimates for $\alpha$ and $\beta$ based on 521 plan families, summarized in Table 8. All plan families exhibit quantity discounting, with digital plan families exhibiting more discounting than analog. In the second stage, we follow BR in assessing how the estimated curvature of the pricing schedule changes with competition by estimating: ${ }^{22}$

$$
\begin{aligned}
\text { Beta }_{i m t}= & \alpha^{C}+\beta_{1}^{C} \text { Prov_Tech }_{i m}+\beta_{2}^{C} \text { Plan_Type }_{i m} \\
& +\beta_{3}^{C}\left(\text { Prov_Tech }_{i m}\right)\left(\text { Plan_Type }_{i m}\right)\left(\text { Entrants }_{m}\right)+\beta_{\geq 4}^{C} \mathbf{X}_{\text {im }}^{C}+\xi_{\text {imt }}^{C} \\
\equiv & f^{C}\left[\alpha^{C}, \beta^{C}, \mathbf{Z}_{\text {imt }}^{C}\right]+\xi_{\text {im } t}^{C} .
\end{aligned}
$$

We augment equation (10) with our adoption and entry equations, equations (3) and (5), in a system-of-equations FIML.

Direct and Indirect Effects. - The results, shown in Table 9, suggest that the increased plan variety for high-usage customers is associated with lower prices. ${ }^{23}$ Competition directly increases analog pricing schedule by 0.09 and introduces a digital pricing schedule that has a much greater curvature (by 0.40 ) than the original analog pricing schedule. Firms transitioning to full digital increase the magnitude of quantity

\footnotetext{
${ }^{22}$ Our estimation of the second stage departs from BR's procedure. They incorporate the estimated standard deviation of the residuals of each plan family's price-quantity regression into an FGLS procedure using all price observations. The FGLS procedure does not control for the endogeneity of entry as BR acknowledge, resulting in upper-bound estimates of competition's effect on curvature. FGLS estimates using our data were consistent with a range of responses to entry from quantity discounting to premia.

${ }^{23}$ We verified that prices fall overall with increased competition. We regressed the minimum price for $180 \mathrm{~min}$ utes of usage for all plan families in 1996 and 1998 on the same variables as in equation (10) plus a year dummy. Prices fall with entry, although not all the coefficients are significant. The results are robust to using 2SLS to control for endogeneity of entry and to using minimum prices at 500 minutes.
} 
TABle 9-Curvature of InCUMBEnts' and EnTRants' 1998 PRICING SCHEDUles: FIML Estimation

\begin{tabular}{|c|c|c|}
\hline & Coefficient & $\begin{array}{l}\text { Standard } \\
\text { error }\end{array}$ \\
\hline \multicolumn{3}{|l|}{ Provider and plan characteristics } \\
\hline Prov_Analog & $-0.076 *$ & 0.057 \\
\hline Prov_Mixed & $-0.167 * *$ & 0.032 \\
\hline Plans_Digital & $-0.230 * *$ & 0.033 \\
\hline Entrant_YN & 0.001 & 0.028 \\
\hline \multicolumn{3}{|l|}{ Market structure } \\
\hline Prov_Analog $\times$ Competitors & $-0.026 * *$ & 0.011 \\
\hline Prov Digital $\times$ Competitors & $-0.022 * *$ & 0.010 \\
\hline Prov_Mixed $\times$ Plans_Analog $\times$ Competitors & 0.003 & 0.011 \\
\hline Prov_Mixed $\times$ Plans_Digital $\times$ Competitors & 0.011 & 0.011 \\
\hline \multicolumn{3}{|l|}{ Market characteristics } \\
\hline$\%$ with BA & $-0.002 *$ & 0.001 \\
\hline Commuting time & $0.003^{* *}$ & 0.002 \\
\hline Population & $-3.5 \mathrm{E}-04$ & 0.000 \\
\hline Household income & $0.003 * *$ & 0.001 \\
\hline $\mathrm{SD}, \eta^{\text {curv }}$ & $0.087 * *$ & 0.037 \\
\hline Fixed effects & \multicolumn{2}{|c|}{ Provider level } \\
\hline Log-likelihood & \multicolumn{2}{|c|}{339.41} \\
\hline Observations & \multicolumn{2}{|c|}{521} \\
\hline
\end{tabular}

Notes: Provider fixed-effects included in plan curvature and digital adoption decision equations. Provider-level clustered standard errors based on 50 bootstrapped samples. The estimated coefficients of the two auxiliary equations, with the corresponding bootstrap standard errors in parentheses, are:

$$
\begin{aligned}
& E N T R A N T S=\underset{(0.0330)}{0.169 P O P}-\underset{(0.0003)}{0.002} P O P^{2}+\underset{(0.0783)}{0.170 A R E A}+\underset{(0.0523)}{0.112 \% C O M M}+\underset{(0.1610)}{0.421 W R I}+\varepsilon^{E} \\
& A D O P T I O N=0.127 \underset{(0.1849)}{E N T R A N T S}-\underset{(0.0265)}{0.044} \text { BAPLUS }-0.050 \underset{(0.0418)}{\operatorname{COMMUTE}}+\underset{(0.0276)}{0.063} \text { POP }
\end{aligned}
$$

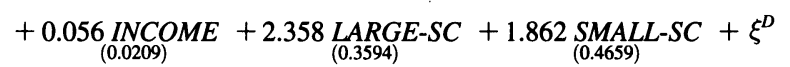

The variables are defined in the footnote to Table 4 . The estimated covariances $\left\{\sigma_{D E}, \sigma_{E P}, \sigma_{D P}\right\}$ are $\{0.008,0.062,-0.016\}$. The estimated variances $\left\{\sigma_{D}^{2}, \sigma_{P}^{2}\right\}$ are $\{0.041,0.014\}$.

** Significant at the 5 percent level.

*Significant at the 10 percent level.

discounting, especially analog- and digital-only providers. An additional firm in the market decreases the curvature of the nonlinear pricing schedule by 0.03 for analogonly providers and 0.02 for digital-only providers, relative to an average curvature of 0.63 and 0.48 , respectively. Competition also has a significant indirect effect on quantity discounting. Transitioning from an analog to a mixed provider decreases the curvature of the digital pricing schedule to 0.23 below that of an analog-only provider.

\section{Conclusion}

Firms in communications and information services industries usually market their products using nonlinear pricing plans and frequently introduce new generations of services. How market structure affects these interdependent choices is assessed by two relevant but distinct strands of literature: one focused on market structure's effect on 
product diffusion and another on its effect on second-degree price discrimination. We empirically estimate market structure's joint effect on adoption and pricing to quantify their relative effects. We examine the effect of entry on firms' pricing responses in the context of new technology diffusion. Our setting allows us to control for unobservable determinants of both the market structure and the behaviors of interest. We find economically significant effects of market structure on both adoption and pricing.

Our results are consistent with lower concentration speeding up technology adoption and stimulating marketing of the technology. Incumbents in markets with more competitors are more likely to transition from analog to digital transmission technologies. This is consistent with cellular incumbents anticipating that significant entry of digital competitors would largely eliminate the market for analog service. This incentive exceeded that of waiting until the cost of deploying the technology fell further.

Lower concentration is also associated with firms marketing the new technology more aggressively by offering more plans and spreading their plans more evenly across the usage spectrum. This is consistent with firms' increased incentive to "fill the calling plan space" and steal customers when facing a larger set of competitors. Prices decline most for high-volume customers.

Our results on the interaction between firms' pricing strategies and technology adoption suggest the need for a more detailed analysis of the effect of technology adoption on subscribers' usage choices and therefore consumer welfare. Usage data would also allow a more detailed analysis of competition's effect on the nonlinear pricing plans available to different customer types and therefore a welfare assessment of the effect of plan variety.

\section{APPENDIX}

\section{A. Adoption Model}

In this Appendix, we derive conditions that determine an incumbent's technology adoption decision in the face of entry by $n$ competitors who have pre-committed to adopting a new technology. ${ }^{24}$ We tailor a subgame of the Fudenberg and Tirole (henceforth FT) (1986) model to analyze whether an incumbent chooses to adopt at a time $t_{1}$, before the entrants' pre-committed adoption time $t_{2}$, or to adopt only after entry at a time $t_{3}$, continuing to use the pre-existing technology in the meantime. ${ }^{25}$

We apply the model to information and communications services industries, such as cellular services, which share the following characteristics. First, competition in these industries can be regarded as differentiated Bertrand since output can be changed easily once capacity is set and marginal costs are nearly zero in the absence of capacity constraints. Second, most innovations in these industries are product rather than

\footnotetext{
${ }^{24}$ In addition to being unable to deter entry, the incumbents' ability to delay entry in our setting is also limited since the FCC required PCS license holders to meet specific coverage requirements within a five-year time window to maintain their licenses.

${ }^{25} \mathrm{As}$ in FT, we derive the equilibrium for a single incumbent to simplify the exposition. We can extend their setup to two incumbents and $\mathrm{n}$ pre-committed entrants, allowing the incumbents to pre-empt each other strategically in their adoption timing of a cost-reducing innovation. We have chosen not to do so here to focus attention on the incumbent's reaction to entry.
} 
process innovations since marginal production costs are nearly zero. ${ }^{26}$ Finally, in these industries, post-entry profits under the old technology are usually more adversely affected by entry than those under the new technology, as we discuss below. Given these assumptions, we find that the incumbent's propensity to adopt prior to entry increases in the number of entrants, at least when faced with many entrants.

If the incumbent adopts at time $t$ before entry, the net present value of its future profits is:

$$
V_{1}=\int_{0}^{t} \Pi_{0}^{I} e^{-r x} d x+\int_{t}^{t_{2}} \Pi_{1}^{I} e^{-r x} d x+\int_{t_{2}}^{\infty} \Pi_{1}^{E} e^{-r x} d x-f(t) e^{-r t},
$$

where $\Pi_{0}^{I}$ denotes the incumbent's flow profits on the old technology before entry, $\Pi_{1}^{I}$ the incumbent's flow profits on the new technology before entry, and $\Pi_{1}^{E}$ the incumbent's flow profits on the new technology after entry. As in FT, we assume that $\Pi_{0}^{I}<\Pi_{1}^{I}$. $f(t)$ denotes the one-time cost of adopting the technology, which is decreasing and convex in the adoption time. The optimal time of adoption, $t_{1}$, occurs when:

$$
t_{1}=\min \left(t_{2}, t:-\left(\Pi_{1}^{I}-\Pi_{0}^{I}\right) e^{-r t}-\frac{d\left[f(t) e^{-r t}\right]}{d t}=0\right) .
$$

If, on the other hand, the incumbent adopts after entry occurs, the net present value of its future profits is:

$$
V_{3}=\int_{0}^{t_{2}} \Pi_{0}^{I} e^{-r x} d x+\int_{t_{2}}^{t} \Pi_{0}^{E} e^{-r x} d x+\int_{t}^{\infty} \Pi_{1}^{E} e^{-r x} d x-f(t) e^{-r t}
$$

where $\Pi_{0}^{E}$ is the incumbent's flow profit on the old technology after entry, and we assume that $\Pi_{0}^{E}<\Pi_{1}^{E}$. $t_{3}$ is determined by:

$$
t_{3}=\max \left(t_{2}, t:-\left(\Pi_{1}^{E}-\Pi_{0}^{E}\right) e^{-r t}-\frac{d\left[f(t) e^{-r t}\right]}{d t}=0\right)
$$

Simplifying, we get:

$$
\begin{aligned}
& V_{1}=\frac{1-e^{-r t_{1}}}{r} \Pi_{0}^{I}+\frac{e^{-r t_{1}}-e^{-r t_{2}}}{r} \Pi_{1}^{I}+\frac{e^{-r t_{2}}}{r} \Pi_{1}^{E}-f\left(t_{1}\right) e^{-r t_{1}}, \text { and } \\
& V_{3}=\frac{1-e^{-r t_{2}}}{r} \Pi_{0}^{I}+\frac{e^{-r t_{2}}-e^{-r t_{3}}}{r} \Pi_{0}^{E}+\frac{e^{-r t_{3}}}{r} \Pi_{1}^{E}-f\left(t_{3}\right) e^{-r t_{3}} .
\end{aligned}
$$

\footnotetext{
${ }^{26}$ Although the digital technology reduces the cost of providing cellular services through better capacity management, such cost reductions are largely unaffected by the number of competitors. In contrast, FT assume that the innovation reduces costs.
} 
The incumbent adopts prior to entry when $V_{1}-V_{3}>0$. We can now determine how the number of entrants, $n$, affects the incumbent's adoption decision. The number of entrants affects only the incumbent's flow profits after entry, $\Pi_{0}^{E}$ and $\Pi_{1}^{E}$. In turn, $t_{3}$ adjusts according to equation (A4). Changes in the number of entrants alter whether the incumbent adopts before or after the entrants, depending on the sign of:

$$
\frac{d\left(V_{1}-V_{3}\right)}{d n}=\left(\frac{e^{-r t_{2}}-e^{-r t_{3}}}{r}\right) \frac{d\left(\Pi_{1}^{E}-\Pi_{0}^{E}\right)}{d n} \cdot{ }^{27}
$$

Therefore, if the incremental flow profits from adopting subsequent to entry increase in the number of entrants, $d\left(\Pi_{1}^{E}-\Pi_{0}^{E}\right) / d n>0$, then additional entry makes it (weakly) more likely that the incumbent adopts prior to entry.

Let $p_{0}^{E}(n)$ be the price of the incumbent's old-technology service and $p_{1}^{E}(n)$ be the incumbent's price of new-technology service. The incumbent's price for new-technology service declines directly with the number of rivals and for old-technology service indirectly since the two services are substitutes, so that $d p_{0}^{E} / d n, d p_{1}^{E} / d n<0$.

Let $q_{0}^{E}\left(p_{0}^{E}(n), p_{1}^{E}(n), n\right)$ and $q_{1}^{E}\left(p_{1}^{E}(n), n\right)$ denote demand faced by the incumbents for usage on the old and new technologies, respectively. ${ }^{28}$ Then we can decompose the effect of entry on incremental flow profits as:

$$
\begin{aligned}
\frac{d\left(\Pi_{1}^{E}-\Pi_{0}^{E}\right)}{d n}= & \frac{d p_{1}^{E}}{d n} q_{1}^{E}+p_{1}^{E}\left(\frac{\partial q_{1}^{E}}{\partial p_{1}^{E}} \frac{d p_{1}^{E}}{d n}+\frac{\partial q_{1}^{E}}{\partial n}\right)-\frac{d p_{0}^{E}}{d n} q_{0}^{E} \\
& -p_{0}^{E}\left[\frac{\partial q_{0}^{E}}{\partial p_{1}^{E}} \frac{d p_{1}^{E}}{d n}+\frac{\partial q_{0}^{E}}{\partial n}+\frac{\partial q_{0}^{E}}{\partial p_{0}^{E}} \frac{d p_{0}^{E}}{d n}\right]
\end{aligned}
$$

This expression simplifies to:

$$
\begin{aligned}
\frac{d\left(\Pi_{1}^{E}-\Pi_{0}^{E}\right)}{d n}= & \frac{d p_{1}^{E}}{d n}\left(1+\varepsilon_{1}^{E}-\frac{\operatorname{Rev}_{0}^{E}}{\operatorname{Rev}_{1}^{E}} \varepsilon_{01}^{E}\right) q_{1}^{E}-\frac{d p_{0}^{E}}{d n}\left(1+\varepsilon_{0}^{E}\right) q_{0}^{E} \\
& +\left(p_{1}^{E} \frac{\partial q_{1}^{E}}{\partial n}-p_{0}^{E} \frac{\partial q_{0}^{E}}{\partial n}\right)
\end{aligned}
$$

where $\varepsilon_{0}^{E}$ is the elasticity of demand for the incumbent's old-technology service, $\varepsilon_{1}^{E}$ is the elasticity of demand for the incumbent's new-technology service, $\varepsilon_{01}^{E}$ is the cross-price elasticity of demand between the two services, $\operatorname{Rev}_{0}^{E}$ is the incumbent's old-technology revenues, and $\operatorname{Rev}_{1}^{E}$ is the incumbent's new-technology revenues.

\footnotetext{
${ }^{27}$ Note that the remaining terms in the derivative of $\left(V_{1}-V_{3}\right)$ with respect to $n$ equal zero since the incumbent chooses its post-entry adoption timing optimally.

${ }^{28}$ If the incumbent adopts the digital technology, consumers cannot substitute to the analog technology. In information and communications services, the new technology usually supplants the old.
} 
Therefore, the incumbent is (weakly) more likely to adopt prior to entry when its post-entry demand for new-technology service exceeds or is more elastic than the demand for old-technology service. Adoption occurs (weakly) earlier when the price for new-technology service is more sensitive to the number of entrants than the price for old-technology service or the demand for the old-technology service is more sensitive to the number of entrants than demand for the new-technology service. Finally, the incumbent is (weakly) more likely to adopt prior to entry when its revenues from new-technology exceed those from old-technology service and the two services are not close substitutes.

In information and communications services industries, there are a number of reasons why post-entry profits under the old technology are likely more adversely affected by entry than those under the new technology. In these industries, revenues from new services tend to quickly exceed those of previous technologies. As discussed in Section II, the number of subscribers to digital quickly overtook those to analog service, suggesting that analog-service demand declined significantly in the presence of even a few entrants. New entrants usually offer the latest technology, as they did in cellular services, suggesting that the price of the new service is more sensitive to the number of entrants than the price of the old service. Lastly, the elasticity of the incumbents' residual demand elasticity for the new service is likely greater than its residual demand elasticity on the old service, at least if it faces significant entry. In cellular services incumbents faced on average 2.16 entrants.

\section{B. Estimation Procedure}

Our system-of-equation results rely on full information maximum likelihood estimators that maximize the likelihood:

$$
L=\prod_{m=1}^{M} L_{m}
$$

In estimating the system of equations with the number of plan introductions as our dependent variable, the contribution to the likelihood from market $m$ is:

$$
L_{m}=\operatorname{Pr}\left(\text { Entrants }_{m}=j, \text { Digital }_{i m}=k_{i}, \Delta \text { Plans }_{i m t}=l_{i t} \forall i, t\right),
$$

where $j$ is an index of the number of entrants, $k_{i}$ equals one if firm $i \in\{1,2, \ldots, I\}$ implements the digital technology and zero otherwise, and $l_{i t}$ indexes the change in the number of plans in firm $i$ 's plan family for technology $t \in\{$ analog, digital $\}$. This equals:

$$
\begin{gathered}
\operatorname{Pr}\left(C_{j}^{E}-f^{E}<\varepsilon_{m}^{E}<C_{j+1}^{E}-f^{E}, \xi_{i m}^{D}<\left(2 k_{i}-1\right) f_{i}^{D},\right. \\
\left.C_{l_{i t}}^{P}-f_{i t}^{P}<\xi_{i m t}^{P}<C_{l_{i t}+1}^{P}-f_{i t}^{P} \forall i, t\right),
\end{gathered}
$$


where $C_{j}^{E}$ is the cutoff for $j$ entrants and $C_{l}^{P}$ is the cutoff for a change of $l$ in the number of plans offered. This probability is given by the integral of the $3 I+1$-dimensional ${ }^{29}$ normal distribution of $\xi_{i m}^{D}, \xi_{i m t}^{P}$, and $\varepsilon_{m}^{E}$ with mean zero and variance-covariance matrix given by ( $I$ is the identity matrix and $\Xi$ is a matrix of all ones):

$$
\Sigma=\left[\begin{array}{ccc}
\sigma_{D}^{2} \boldsymbol{\Xi}_{I \times I}+\mathbf{I}_{I \times I} & \sigma_{D P} \boldsymbol{\Xi}_{I \times 2 I} & \sigma_{D E} \mathbf{I}_{I \times 1} \\
\sigma_{D P} \boldsymbol{\Xi}_{2 I \times I} & \sigma_{P}^{2} \boldsymbol{\Xi}_{2 I \times 2 I}+\mathbf{I}_{2 I \times 2 I} & \sigma_{P E} \mathbf{I}_{2 I \times 1} \\
\sigma_{D E} \mathbf{I}_{1 \times I} & \sigma_{P E} \mathbf{I}_{1 \times 2 I} & 1,
\end{array}\right],
$$

over the surface defined by $f^{D} ; f^{P}$ and the cutoffs $C_{-5}^{P}$ through $C_{9}^{P}$; and $f^{E}$ and the cutoffs $C_{1}^{E}$ through $C_{4}^{E}$ that are consistent with the observed technology, change in plans offered, and number of entrants, respectively. The variance-covariance matrix in equation (A12) allows for correlation in the unobservable market shifters of the adoption, plan change, and entry equations, and thus controls for the endogeneity of market structure across equations.

The assumption that $\xi_{i m}^{D}=\varepsilon_{m}^{D}+\eta_{\text {im }}^{D}$ and $\xi_{\text {imt }}^{P}=\varepsilon_{m}^{P}+\eta_{\text {imt }}^{P}$ with $\eta_{i m}^{D} \sim N(0,1)$ and $\eta_{i m t}^{P} \sim N(0,1)$ allows us to simplify the likelihood by integrating out $\eta_{i m}^{D}$ and $\eta_{\text {imt }}^{P}$. This results in:

(A13) $L_{m}=\int_{C_{j}^{E}-f^{E}}^{C_{j+1}^{E}-f^{E}} \int_{-\infty}^{\infty} \int_{-\infty}^{\infty} \prod_{i=1}^{I}\left[g_{i}^{D}\left(\varepsilon^{D}\right) \prod_{t \in\{\mathrm{A}, \mathrm{D}\}} g_{i t}^{P}\left(\varepsilon^{P}\right)\right] \phi\left(\varepsilon^{D}, \varepsilon^{P}, \varepsilon^{E}\right) d \varepsilon^{D} d \varepsilon^{P} d \varepsilon^{E}$

where

$$
\begin{aligned}
& g_{i}^{D}\left(\varepsilon^{D}\right)=\Phi\left(f_{i}^{D}+\varepsilon^{D}\right)^{k_{i}}\left(1-\Phi\left(f_{i}^{D}+\varepsilon^{A}\right)\right)^{1-k_{i}} \\
& g_{i t}^{P}\left(\varepsilon^{P}\right)=\Phi\left(C_{l_{i t}+1}^{P}-f_{i t}^{P}-\varepsilon^{P}\right)-\Phi\left(C_{l_{i t}^{P}}^{P}-f_{i t}^{P}-\varepsilon^{P}\right)
\end{aligned}
$$

and $\phi\left(\varepsilon^{D}, \varepsilon^{P}, \varepsilon^{E}\right)$ refers to the pdf of the trivariate normal distribution of $\left(\varepsilon^{D}, \varepsilon^{P}, \varepsilon^{E}\right)$ in equation (7). We further integrate $\varepsilon_{m}^{E}$ out of the likelihood, conditioning on $\varepsilon_{m}^{D}$ and $\varepsilon_{m}^{P}$ to obtain:

$$
\begin{aligned}
L_{m}= & \int_{-\infty}^{\infty} \int_{-\infty}^{\infty} \prod_{i=1}^{I}\left[g_{i}^{D}\left(\varepsilon^{D}\right) \prod_{t \in\{A, D\}} g_{i t}^{P}\left(\varepsilon^{P}\right)\right] \\
& \times\left[\Phi_{\varepsilon^{E} \mid \varepsilon^{D}, \varepsilon^{P}}\left(C_{j+1}^{E}-f^{E}\right)-\Phi_{\varepsilon^{E} \mid \varepsilon^{D}, \varepsilon^{P}}\left(C_{j}^{E}-f^{E}\right)\right] \phi\left(\varepsilon^{D}, \varepsilon^{P}\right) d \varepsilon^{D} d \varepsilon^{P}
\end{aligned}
$$

where $\Phi_{\varepsilon^{E} \mid \varepsilon^{D}, \varepsilon^{P}}$ denotes the conditional cdf of $\varepsilon^{E}$, given realizations of $\varepsilon^{D}$ and $\varepsilon^{P}$.

\footnotetext{
${ }^{29}$ This results from stacking the $I$ adoption errors $\xi_{i m}^{D}$, the $2 I$ technology-specific plan-change errors $\xi_{i m t}^{P}$ and the single market-level error $\varepsilon_{m}^{E}$. The dimensionality of the plan change errors is less than $2 I$ in the data since not all firms offer both analog and digital plan families in all markets.
} 
For the continuous plan variety measures, the likelihood of observing the firms' technology adoption and plan variety choices across plan technologies in market $m$ becomes (where $v_{i t}$ equals the observed variety measure for firm $i$ 's plan family for technology $t)$ :

$$
\begin{aligned}
& \operatorname{Pr}\left(\text { Entrants }_{m}=j, \text { Digital }_{i m}=k_{i}, \text { Variety }_{i m t}=v_{i t} \forall i, t\right) \\
& =\operatorname{Pr}\left(C_{j}^{E}-f^{E}<\varepsilon_{m}^{E}<C_{j+1}^{E}-f^{E}, \xi_{i m}^{D}<\left(2 k_{i}-1\right) f_{i}^{D}, \xi_{i m t}^{P}=v_{i t}-f_{i t}^{P}\right)
\end{aligned}
$$

This entails only one modification of $g_{i t}^{P}\left(\varepsilon^{P}\right)$ above, which now equals the standard normal pdf of $\eta_{\text {imt }}^{P}$ :

$$
g_{i t}^{P}\left(\varepsilon^{P}\right)=\phi\left(v_{i t}-f_{i t}^{P}-\varepsilon^{P}\right) .
$$

For a given value of the parameters, we use simulation techniques to compute each market's contribution to the likelihood in equation (A15) by integrating numerically over the bivariate normal distribution of $\varepsilon^{D}$ and $\varepsilon^{P}$. We then use a numerical maximization routine to maximize the full likelihood in equation (A9) and update the parameters until convergence.

We assess parameter significance using bootstrap samples of 50 replications. We control for non-random clustering of unobservables by firm. For each bootstrap sample, we draw firms from the set in our sample and include the full set of plan families each firm offers across its market. We add firms until the number of observations is at least as large as the number of observations in the actual dataset and the bootstrap sample contains at least one observation for each level of the discrete variables.

\section{REFERENCES}

Borzekowski, Ron, Raphael Thomadsen, and Charles Taragin. 2009. "Competition and Price Discrimination in the Market for Mailing Lists." Quantitative Marketing and Economics, 7(2): 147-79.

Busse, Meghan R. 2000. "Multimarket Contact and Price Coordination in the Cellular Telephone Industry." Journal of Economics and Management Strategy, 9(3): 287-320.

Busse, Meghan, and Marc Rysman. 2005. "Competition and Price Discrimination in Yellow Pages Advertising." RAND Journal of Economics, 36(2): 378-90.

Cameron, A. Colin, and Pravin K. Trivedi. 1986. "Econometric Models Based on Count Data: Comparisons and Applications of Some Estimators and Tests." Journal of Applied Econometrics, 1(1): 29-53.

Cameron, A. Colin, and Pravin K. Trivedi. 2005. Microeconometrics: Methods and Applications. Cambridge, UK: Cambridge University Press.

Cellular Telecommunications and Internet Association. 2000. "Semi-Annual Wireless Industry Survey." http://www.ctia.org/. (accessed February 1, 2008).

Fudenberg, Drew, and Jean Tirole. 1985. "Preemption and Rent Equilization in the Adoption of New Technology." Review of Economic Studies, 52(3): 383-401.

Fudenberg, Drew, and Jean Tirole. 1986. Dynamic Models of Oligopoly. Fundamentals of Pure and Applied Economics, ed. Jacques Lesourne and Hugo Sonnenschein. Chur, Switzerland: Harwood Academic Publishers.

Gal-Or, Esther. 1988. “Oligopolistic Nonlinear Tariffs.” International Journal of Industrial Organization, 6(2): 199-221. 
Gyourko, Joseph, Albert Saiz, and Anita Summers. 2008. "A New Measure of the Local Regulatory Environment for Housing Markets: The Wharton Residential Land Use Regulatory Index." Urban Studies, 45(3): 693-729.

Hamilton, Barton H., and Brian McManus. 2005. "Technology Diffusion and Market Structure: Evidence from Infertility Treatment Markets.” http://www.unc.edu/ mcmanusb/IVFTechSept2005 pdf.

Hannan, Timothy H., and John M. McDowell. 1984. "The Determinants of Technology Adoption: The Case of the Banking Firm.” RAND Journal of Economics, 15(3): 328-35.

Hoppe, Heidrun C. 2002. "The Timing of New Technology Adoption: Theoretical Models and Empirical Evidence." Manchester School, 70(1): 56-76.

Johnson, Justin P., and David P. Myatt. 2003. "Multiproduct Quality Competition: Fighting Brands and Product Line Pruning." American Economic Review, 93(3): 748-74.

Johnson, Justin P., and David P. Myatt. 2006. "Multiproduct Cournot Oligopoly." RAND Journal of Economics, 37(3): 583-601.

Karshenas, Massoud, and Paul L. Stoneman. 1993. "Rank, Stock, Order, and Epidemic Effects in the Diffusion of New Process Technologies: An Empirical Model." RAND Journal of Economics, 24(4): 503-28.

Levin, Sharon G., Stanford L. Levin, and John B. Meisel. 1987. “A Dynamic Analysis of the Adoption of a New Technology: The Case of Optical Scanners." Review of Economics and Statistics, 69(1): 12-17.

Marcon, Eric, and Florence Puech. 2003. "Evaluating the Geographic Concentration of Industries Using Distance-Based Methods.” Journal of Economic Geography, 3(4): 409-28.

McManus, Brian. 2007. "Nonlinear Pricing in an Oligopoly Market: The Case of Specialty Coffee." RAND Journal of Economics, 38(2): 512-32.

Meyers, Jason. 1997. “Cellular Revisited: Afraid to Let PCS Newcomers Tarnish Their Hard-Earned Image, Cellular Operators are Sallying Forth with Enhanced Digital Services and Marketing Efforts." Telephony, March 3. http://connectedplanetonline.com/mag/telecom_cellular_revisited_ afraid/.

Miravete, Eugenio J., and Lars-Hendrik Röller. 2004. "Competitive Nonlinear Pricing in Duopoly Equilibrium: The Early U.S. Cellular Telephone Industry." http://www.eugeniomiravete.com/ papers/EJM-LHR.pdf.

Oren, Shmuel S., Stephen A. Smith, and Robert B. Wilson. 1983. "Competitive Nonlinear Tariffs." Journal of Economic Theory, 29(1): 49-71.

Oster, Sharon. 1982. "The Diffusion of Innovation among Steel Firms: The Basic Oxygen Furnace." Bell Journal of Economics, 13(1): 45-56.

Parker, Philip M., and Lars-Hendrik Röller. 1997. "Collusive Conduct in Duopolies: Multimarket Contact and Cross-Ownership in the Mobile Telephone Industry." RAND Journal of Economics, 28(2): 304-22.

Reinganum, Jennifer F. 1981a. "Market-Structure and the Diffusion of New Technology." Bell Journal of Economics, 12(2): 618-24.

Reinganum, Jennifer F. 1981b. "On the Diffusion of New Technology: A Game Theoretic Approach." Review of Economic Studies, 48(3): 395-405.

Riordan, Michael H. 1992. "Regulation and Preemptive Technology Adoption.” RAND Journal of Economics, 23(3): 334-49.

Rose, Nancy L., and Paul L. Joskow. 1990. "The Diffusion of New Technologies: Evidence from the Electric Utility Industry." RAND Journal of Economics, 21(3): 354-73.

Saiz, Albert. 2010. “The Geographic Determinants of Housing Supply.” Quarterly Journal of Econom ics, 125(3): 1253-96.

Spulber, Daniel F. 1989. "Product Variety and Competitive Discounts." Journal of Economic Theory, 48(2): 510-25.

Stole, Lars A. 1995. "Nonlinear Pricing and Oligopoly." Journal of Economics and Management Strategy, 4(4): 529-62.

Yang, Huanxing, and Lixin Ye. 2008. "Nonlinear Pricing, Market Coverage, and Competition.” Theoretical Economics, 3(1): 123-53. 